\title{
$\beta$-Catenin Overexpression in the Metanephric Mesenchyme Leads to Renal Dysplasia Genesis via Cell-Autonomous and Non-Cell-Autonomous Mechanisms
}

\author{
Sanjay Sarin, ${ }^{*}$ Felix Boivin, ${ }^{*}$ Aihua Li, ${ }^{*}$ Janice Lim, ${ }^{*}$ Bruno Svajger, ${ }^{*}$ Norman D. Rosenblum, ${ }^{\dagger}$ and Darren Bridgewater* \\ From the Program in Pathology and Molecular Medicine, ${ }^{*}$ McMaster University, Hamilton, Ontario, Canada; and the Division of Nephrology, ${ }^{\dagger}$ the \\ Department of Pediatrics, The Hospital for Sick Children, University of Toronto, Toronto, Ontario, Canada
}

\author{
Accepted for publication \\ January 7, 2014. \\ Address correspondence to \\ Darren Bridgewater, Ph.D., \\ Program in Pathology and \\ Molecular Medicine, McMaster \\ University Medical Centre, \\ 1200 Main St W, Hamilton, \\ ON, Canada L8N 3Z5. E-mail: \\ bridgew@mcmaster.ca.
}

\begin{abstract}
Renal dysplasia, a developmental disorder characterized by defective ureteric branching morphogenesis and nephrogenesis, ranks as one of the major causes of renal failure among the pediatric population. Herein, we demonstrate that the levels of activated $\beta$-catenin are elevated in the nuclei of ureteric, stromal, and mesenchymal cells within dysplastic human kidney tissue. By using a conditional mouse model of mesenchymal $\beta$-catenin overexpression, we identify two novel signaling pathways mediated by $\beta$-catenin in the development of renal dysplasia. First, the overexpression of $\beta$-catenin within the metanephric mesenchyme leads to ectopic and disorganized branching morphogenesis caused by $\beta$-catenin directly binding Tcf/lef consensus binding sites in the Gdnf promoter and up-regulating $G d n f$ transcription. Second, $\beta$-catenin overexpression in the metanephric mesenchyme leads to elevated levels of transcriptionally active $\beta$-catenin in the ureteric epithelium. Interestingly, this increase of $\beta$-catenin-mediated transcription results from a novel Ret/ $\beta$-catenin signaling pathway. Consistent with these findings, analysis of human dysplastic renal tissue demonstrates that undifferentiated mesenchymal cells expressing high levels of $\beta$-catenin also express increased GDNF. Furthermore, dysplastic ureteric tubules that were surrounded by high levels of GDNF also exhibited increased levels of activated $\beta$-catenin. Together, these data support a model in which the elevation of $\beta$-catenin in the metanephric mesenchyme results in cell-autonomous and non-cellautonomous events that lead to the genesis of renal dysplasia. (Am J Pathol 2014, 184: 1395-1410; http://dx.doi.org/10.1016/j.ajpath.2014.01.018)
\end{abstract}

Human renal dysplasia is a severe form of congenital kidney malformation that affects up to 1 in 1000 of the general population $^{1}$ and is one of the leading causes of childhood endstage kidney disease. ${ }^{2}$ Despite the high prevalence of renal dysplasia, the underlying pathological mechanisms are poorly understood and no treatments are readily available. Dysplastic kidneys exhibit varying degrees of gross and histopathological changes, including large kidneys with cysts of varying size and location, abnormal patterning of tissue elements, poorly differentiated cystic epithelia and mesenchymalderived tubules, and metaplastic transformation of mesenchyme to cartilage. ${ }^{1-6}$ Defects in ureteric epithelial branch patterning and subsequent collecting duct differentiation and nephron induction are major contributing factors that lead to the gross and histopathological changes observed in renal dysplasia; however, the molecular mechanisms are not well understood. ${ }^{4,7}$

Ureteric branching begins with the emergence of the ureteric bud, an outgrowth off the caudal Wolffian duct, in response to signals originating in the metanephric mesenchyme. The ureteric bud migrates into the adjacent metanephric mesenchyme and undergoes a process of growth, elongation, and branching to form the collecting duct system of the kidney. In a reciprocal manner, the tips of the ureteric epithelium induce a subset of mesenchyme to

Supported by a Hamilton Health Sciences new investigator award (D.B.), the Kidney Foundation of Canada, the J. P. Bickell Foundation, and Natural Sciences and Engineering Research Council of Canada.

Disclosures: None declared. 
undergo nephrogenesis, which will form the functional units of the kidney, termed nephrons. ${ }^{8}$ Central to growth of the ureteric epithelium is the GDNF/RET signaling pathway. The secreted growth factor GDNF is expressed in the metanephric mesenchyme, whereas its cell surface coreceptors RET and Gdnf family receptor $\alpha 1$ are co-expressed in the Wolffian duct, ureteric bud, and tips of its daughter branches. ${ }^{9,10}$ Binding of GDNF to its coreceptors results in the stimulation of the RET receptor and activation of numerous downstream intracellular signaling pathways, including the RAS/extracellular signal-regulated kinase mitogen-activated protein kinase, phosphatidylinositol-3kinase, and phospholipase $\mathrm{C}-\gamma$ pathways. Together, these signaling pathways mediated by RET activation lead to changes in gene expression that promote proliferation, cell rearrangements, changes in cell shape, and cell movements leading to the outgrowth of the ureteric bud and branching morphogenesis. ${ }^{11-13}$ Genetic deletion of Gdnf, Ret, or Gfral results in renal aplasia or hypodysplasia due to a failure in ureteric budding. Despite the critical contribution of this signaling system to kidney development, the factors regulating expression of these genes are not completely understood. ${ }^{14,15}$

Kidney formation is also regulated by members of the Wnt family of secreted glycoproteins. ${ }^{16-19}$ Wnt proteins execute their functions by activating canonical or noncanonical mediated signaling pathways. ${ }^{20}$ The canonical Wnt signaling pathway involves cytoplasmic accumulation and translocation of the protein $\beta$-catenin into the nucleus, where it activates gene transcription. ${ }^{21} \beta$-Catenin is a multifunctional protein involved in cell-cell adhesion by associating with E-cadherin and $\alpha$-catenin and linking the actin cytoskeleton with adherens junctions, whereas in the nucleus, it acts as a transcriptional activator with Tcf/Lef family members. During kidney development, both nephrogenic induction and ureteric morphogenesis require $\beta$-catenin signaling. Loss of $\beta$-catenin from nephron progenitors inhibits nephron formation due to reduced expression of key genes required in nephrogenesis, including Fgf8, Pax8, Wnt4, and Lhxl. ${ }^{19}$ In the ureteric epithelium, homozygous $\beta$-catenin deficiency results in premature differentiation of the collecting system, and a deficiency in the expression of Emx2, Lim1, Pax2, Ret, and Wnt11, genes required for branching morphogenesis. ${ }^{22-24} \mathrm{We}$ have previously shown that $\beta$-catenin is overexpressed in the ureteric epithelium in human dysplastic renal tissue and in distinct genetic mouse models of renal dysplasia., ${ }^{3,25}$ Generation of a mouse model in which $\beta$-catenin levels were elevated exclusively in the ureteric epithelium during kidney development resulted in a block in ureteric differentiation and up-regulation of $T g f \beta 2$ and $D k k l$, resulting in the genesis of renal dysplasia. ${ }^{25}$ However, it is not clear if a functional role for $\beta$-catenin in the genesis of renal dysplasia exists in other cells of the kidney.

Herein, we demonstrate that the transcriptionally active form of $\beta$-catenin localizes to the nucleus of ureteric epithelium, stroma, and mesenchyme, in dysplastic human renal tissue. To understand the pathological significance of $\beta$-catenin overexpression in renal dysplasia, we generated mutant mice in which $\beta$-catenin is overexpressed in the kidney mesenchyme and demonstrated histopathological changes remarkably consistent with human renal dysplasia. The histopathological changes observed in our mutant mice resulted from the activation of two novel genetic pathways, both mediated by $\beta$-catenin. In the metanephric mesenchyme, the overexpression of $\beta$-catenin directly regulates $G d n f$ expression and also activates a novel Ret/ $\beta$-cateninmediated signaling pathway within the ureteric epithelium. Together, these novel pathways resulted in the genesis of renal dysplasia through ectopic and disorganized ureteric branching.

\section{Materials and Methods}

\section{Mouse Strains}

Rarß2-Cre (Cre expression limited to the metanephric mesenchyme) (Supplemental Figure S1) male mice were crossed with female mice containing LoxP sites flanking exon 3 of the $\beta$-catenin allele $\left(\beta \text {-cat }{ }^{\Delta 3 / \Delta 3}\right)^{26}$ to generate $\beta$-catenin gain-of-function mutant progeny, termed $\beta$-cat ${ }^{G O F-M M}$. The Cre transgene was detected in mouse tail DNA using primers $5^{\prime}$-GCGGCATGGTGCAAGTTGAAT-3' and 5'-CGTTCACCGGCATCAACGTTT- $3^{\prime}$. Tcf- $\beta$-galactosidase reporter mice ${ }^{27}$ were crossed with $\beta$-cat ${ }^{\Delta 3 / \Delta 3}$ to generate female $T c f /$ LacZ; $\beta$-cat ${ }^{\Delta 3 /+}$ mice. Female TcflLacZ; $\beta$-cat ${ }^{\Delta 3 /+}$ mice were then crossed with male Rar $\beta 2$-Cre mice to generate $T c F /$ $L a c Z ; \beta-c a t^{G O F-M M}$ mice and used to visualize $\beta$-catenin transcriptional activity in the ureteric epithelium. ${ }^{22,25}$ Rar $\beta 2$-Cre male mice were crossed with female mice containing LoxP sites flanking exons 2 through $6^{28}$ to generate Rar $32-C r e$; $\beta$-cat ${ }^{+/-}$males. These males were then mated to homozygous $\beta$-catenin conditional knockout females to generate homozygous $\beta$-catenin loss-of-function mutants in the mesenchyme, termed $\beta$-cat ${ }^{L O F-M M}$. The Cre transgene was detected in mouse tail DNA using primers $5^{\prime}$-GCGGCATGGTGCAAGTTGAAT- $3^{\prime}$ and $5^{\prime}$-CGTTCACCGGCATCAACGTTT- $3^{\prime}$. To detect the $\beta$-catenin floxed allele, primers $5^{\prime}$-AAGGTAGAGTGATGAAAGTTGTT- $3^{\prime}$ and $5^{\prime}$-CACCATGTCCTCTGTCTATTC- $3^{\prime}$ were used. ${ }^{28}$ Rar $\beta 2-C r e$ mice were crossed with $G t(R O S A) 26 \operatorname{Sor}(R O S A)$ mice to analyze the spatial Cre recombinase activity. ${ }^{29}$ In all instances, 12 PM on the day of vaginal plug detection was considered to be E0.5. Animal studies were done in accordance with animal care and institutional guidelines.

\section{Human Kidney Dysplastic Tissue}

One-year post-natal and 38-week dysplastic human renal tissues were obtained from the McMaster University (Hamilton, ON, Canada) pathology department in accordance with research ethics (Research Ethics Board approval 13-160-T). 


\section{Histological Data}

Whole kidney tissue was fixed in $4 \%$ paraformaldehyde for at least 24 hours at $4^{\circ} \mathrm{C}$. Kidneys were paraffin embedded, divided into sections ( $4 \mu \mathrm{m}$ thick), mounted onto Superfrost Plus slides (Thermo Fisher Scientific, Waltham, MA), and incubated overnight at $37^{\circ} \mathrm{C}$. Sections were deparaffinized using xylene washes and rehydrated using graded ethanol washes $\left(100 \%, 95 \%, 75 \%, 50 \%, \mathrm{H}_{2} 0\right)$ and stained with H\&E (Sigma, St. Louis, MO).

\section{Immunofluorescence and IHC}

Antigen retrieval was performed for 5 minutes in $10 \mathrm{mmol} / \mathrm{L}$ sodium citrate solution ( $\mathrm{pH}$ 6.0) in a pressure cooker, followed by blocking with $7.5 \%$ normal goat serum $/ 4.5 \%$ bovine serum albumin. Sections were incubated with primary antibodies to Six2 (Proteintech Group, Chicago, IL; 1:250 dilution), Pax2 (Covance, Montreal, QC, Canada; 1:200 dilution), cytokeratin (Sigma; 1:200 dilution), Wt-1 (SantaCruz, Dallas, TX; 1:200 dilution), or nephrin (Sigma; 1:200 dilution) overnight at $4^{\circ} \mathrm{C}$. Tissue sections were washed in PBS (pH 7.4), incubated with secondary antibodies Alexa Fluor 488 or 568 (Invitrogen, Carlsbad, CA; 1:1000 dilution) for 1 hour at room temperature, stained with DAPI (Sigma; 1:1000 dilution) for 5 minutes, and coverslipped using Fluoromount (Sigma). Immunohistochemistry (IHC) was performed using the Vectastain elite avidin-biotin complex kit (Vector Labs, Burlingame, CA). After antigen retrieval, endogenous peroxidase activity was blocked using $3 \% \mathrm{H}_{2} \mathrm{O}_{2}$ for 10 minutes, followed by blocking endogenous biotinbinding activity using a biotin/avidin blocking kit (Vector Labs), as per company protocol. Incubation with primary antibodies, including activated $\beta$-catenin (Millipore, Billerica, MA; 1:100 dilution), Pax2 (Covance; 1:200 dilution), and Gdnf (R\&D Systems, Minneapolis, MN; 1:100 dilution), was performed overnight at $4^{\circ} \mathrm{C}$. Sections were washed and incubated in biotinylated secondary antibodies (Vector Labs) for 30 minutes at room temperature. Color reaction was visualized using diaminobenzidine (Vector Labs), and slides were coverslipped using Permount (Thermo Fischer Scientific) and imaged on a Nikon 90i-eclipse upright microscope.

\section{Whole-Mount Immunofluorescence}

Kidneys were flattened on $0.4-\mu \mathrm{m}$ transwell filters (BD, Franklin Lakes, NJ) for 4 hours at $37^{\circ} \mathrm{C}$ in wells containing Dulbecco's minimal essential medium (DMEM) and stored in $100 \%$ methanol at $-20^{\circ}$. Kidneys were washed $3 \times$ with PBS and blocked in $10 \%$ normal goat serum, followed by incubation with primary antibodies to cytokeratin (Sigma; 1:200 dilution) or Pax2 (Covance; 1:200 dilution) at $37^{\circ} \mathrm{C}$ for 1.5 hours. Kidneys were washed in PBS ( $\mathrm{pH} 7.4$ ), incubated with secondary antibodies Alexa Fluor 488 or 568 (Invitrogen; 1:200 dilution) for 1.5 hours at $37^{\circ} \mathrm{C}$, and imaged on a Nikon 90i-eclise inverted microscope.

\section{$\beta$-Galactosidase Staining}

Kidneys were fixed in $0.2 \%$ glutaraldehyde, $100 \mathrm{mmol} / \mathrm{L}$ EGTA (pH 7.3), $1 \mathrm{~mol} / \mathrm{L} \mathrm{MgCl}_{2}, 0.1 \mathrm{~mol} / \mathrm{L}$ sodium phos-

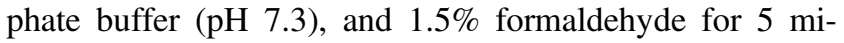
nutes. Kidneys were washed in $1 \mathrm{~mol} / \mathrm{L} \mathrm{MgCl}_{2}, 0.1 \mathrm{~mol} / \mathrm{L}$ sodium phosphate buffer ( $\mathrm{pH} 7.3$ ), and $0.25 \%$ Nonidet $\mathrm{P}-40$, and whole kidney tissue was incubated with X-Gal stain [25 $\mathrm{mg} / \mathrm{mL}$ X-Gal (Bethesda Research Labs, Burlington, ON, Canada), $0.25 \mathrm{mmol} / \mathrm{L}$ potassium ferrocyanide, and 0.25 $\mathrm{mmol} / \mathrm{L}$ potassium ferricyanide]. Kidneys were washed and fixed in $4 \%$ paraformaldehyde and visualized on a Leica EZ4D microscope (Leica, Wetzlar, Germany).

\section{In Situ Hybridization}

In situ hybridization was performed using digoxigeninlabeled chromosomal RNA probes on whole kidney tissue, as previously described. Tissue was hybridized with sense (control) or antisense RNA transcripts for the following genes: Gdnf, Ret, and Wntll (gifts from N.D.R.). Kidneys were imaged using a Leica EZ4D microscope. Mean staining intensity and domain were measured using NIS elements software (version AR 3.22 64-bit; Nikon, Melville, NY).

\section{ChIP Assay}

E14.5 kidney tissue was dissected and cross-linked in $4 \%$ formaldehyde. Cross-linked tissue was homogenized in lysis buffer (1\% SDS, $10 \mathrm{mmol} / \mathrm{L}$ EDTA, and $50 \mathrm{mmol} / \mathrm{L}$ Tris, $\mathrm{pH}$ 8.0) and sonicated to generate DNA fragments of 200 to $1000 \mathrm{bp}$. Soluble chromatin was precleared by protein G agarose/salmon sperm DNA beads (Millipore). Immunoprecipitation was performed using $2 \mu \mathrm{g}$ of mouse anti- $\beta$ catenin antibody (BD), or isotype-specific $\operatorname{IgG}$ (negative control) was added to every $100 \mu \mathrm{L}$ of soluble chromatin to immunoprecipitate $\beta$-catenin-binding DNA. Immune complexes were separated with $G$ agarose/salmon sperm DNA beads, followed by a series of washing buffer with protein inhibitors. Cross-linked protein-DNA compound was disassociated by incubation with DNase-free proteinase $\mathrm{K}$, and RNA residual was removed by RNase A. DNA was purified with a Zymo chromatin immunoprecipitation (ChIP) DNA clean and concentrated kit (Zymo Research, Irvine, CA). Three fragments containing the Tcf-binding sites identified in silico using MULAN were examined by PCR. We designed primers to a site within the $G d n f$ coding region with no consensus $\beta$-catenin-binding site as the nonspecific internal control site. All primers were designed with Primer 3 software version 0.4.0 (http://bioinfo.ut.ee/primer30.4.0, last accessed March 14, 2014).

\section{Real-Time RT-PCR}

Real-time PCR amplification was performed using the 7900HT fast RT-PCR system (Applied Biosystems, 
Burlington, ON, Canada). Real-time PCR reaction mix contained $0.5 \mathrm{ng}$ of each pull-down DNA sample, SYBR Green PCR Master Mix (Applied Biosystems), and 300 $\mathrm{nmol} / \mathrm{L}$ of each primer to a total volume of $25 \mu \mathrm{L}$. Primers for the 4.9-, 2.25-, and 2.1-kb $\beta$-catenin consensus binding sites were designed using the Primer 3 software version 0.4.0 (http://primer3.sourceforge.net/webif.php, last accessed March 14, 2014) and verified using the University of California, Santa Cruz, genome bioinformatics website (http:// genome.ucsc.edu, last accessed January 10, 2011). Primer design was restrictive, the annealing temperature was restricted to $59^{\circ} \mathrm{C}$ to $60^{\circ} \mathrm{C}$, and the length of the PCR product was set between 100 and 200 bp. Specificity of the amplification was performed by agarose gel electrophoresis. Relative levels of pull-down DNA were performed in triplicate using the $2^{\left(-\Delta \Delta \mathrm{C}_{\mathrm{T}}\right)}$ method. ${ }^{30}$ Individual expression values were normalized by comparison to input DNA.

\section{Primer Sequences for ChIP}

Primer sequences were as follows: $4.9-\mathrm{kb}$ site on $5^{\prime}$ untranslated region (UTR) (forward) 5'-TCTCAGCTGCTGTGCCTATG-3' $3^{\prime}$ and (reverse) $5^{\prime}$-GGCAGGTCAGGAGTAAGCAA- $3^{\prime}$; 2.25-kb site on $5^{\prime}$ UTR (forward) $5^{\prime}$-GCAAACCAGCTCTTTCAACA- $3^{\prime}$ and (reverse) $5^{\prime}$-AATTGCTGGACTGAACATGGA-3'; 2.3-kb site on $5^{\prime}$ UTR (forward) $5^{\prime}$-GGGTAATGTGTGTGGCAATG- $3^{\prime}$ and (reverse) $5^{\prime}$ CTTCCCTGCAAGGTGTTGTT-3'; and GDNF coding region (forward) 5'-ACATGCCTGGCCTACTTTGT-3' and (reverse) 5'- GACTTGGGTTTGGGCTATGA-3'.

\section{Constructs of Plasmids}

A 560-bp MluI/HindIII fragment of the $G d n f$ promoter, including the Tcf-binding site TTCAAAG, was amplified from human 293 genomic DNA with primers (forward) 5' ACGCGTTGAGGGGACATTCCAGGCT- $3^{\prime}$ and (reverse) 5'-AAGCTTATCTCCCTTGCCAATGTCAGGA-3'. The amplified fragment was cloned into pGLuc-Basic vector from New England BioLabs (Ipswich, MA). TATA box oligonucleotides were annealed and ligated into the BamHI site to generate the pGluc-4.9kb-TATA. All of the inserts were verified by sequencing.

\section{Cell Culture/Transfection}

Human embryonic kidney (HEK) 293 cells were obtained from ATCC (Manassas, VA) and cultured in DMEMHyclone (Thermo Scientific, Waltham, MA) with $4 \mathrm{mmol} /$ L L-glutamine, supplemented with $10 \%$ fetal bovine serum (PAA, Etobicoke, $\mathrm{ON}$, Canada) at $37^{\circ} \mathrm{C}$ in a $5 \% \mathrm{CO}_{2}$ waterjacketed incubator.

HEK293 cells were seeded into a 24-well plate at $1.0 \times 10^{5}$ per well in $0.5 \mathrm{~mL}$ of growth medium without antibiotics. Twenty-four hours later, HEK293 cells were transfected with pGluc-Basic-TATA or pGluc-4.9kb-TATA per Lipofectamine 2000 manufacturer's instructions (Invitrogen). Twenty-four hours after transfection, conditioned media were collected. Cells were then serum starved overnight (16 hours) and subsequently activated by 40 $\mathrm{mmol} / \mathrm{L}$ lithium chloride (LiCl; Sigma). Media were collected at $0,6,8,10,12$, and 24 hours. Cells were lysed in lysis buffer $(150 \mathrm{mmol} / \mathrm{L} \mathrm{NaCl}, 20 \mathrm{mmol} / \mathrm{L}$ Tris, and $1 \%$ Nonidet P-40, pH 8.0), and lysates were harvested for protein assay.

\section{Gaussia Luciferase Activity Assay}

Gaussia luciferase assays were performed with BioLux Gaussia Luciferase Flex Assay Kit from New England BioLabs, as per manufacturer's instructions. Culture medium (20 $\mu \mathrm{L}$ ) was added into a 96-well opaque plate, and $50 \mu \mathrm{L}$ of Gluc substrate working solution was injected and relative light units were measured by an LB luminometer (Thermo Fisher, Waltham). Gaussia luciferase activity was calculated as total relative light units in the medium and standardized by the total protein of the cells in corresponding wells.

\section{Ex Vivo Organ Culture and Immunoprecipitation}

E14.5 kidneys were resected and grown onto transwell filters at the air-media interface. Kidneys were incubated in DMEM supplemented with $1 \%$ fetal bovine serum. Culture media were switched to DMEM supplemented with or without $100 \mathrm{ng} / \mathrm{mL}$ of GDNF for 3 hours. Protein was isolated from kidney explants by homogenizing in TENT ++ buffer $[0.1 \mathrm{~mol} / \mathrm{L}$ Tris-Cl $(\mathrm{pH} 8.0), 0.01 \mathrm{~mol} / \mathrm{L}$ EDTA (pH 8.0), $1 \mathrm{~mol} / \mathrm{L} \mathrm{NaCl}, 0.2 \%$ Triton X-100, protease inhibitor, and phosphatase inhibitor]. Protein concentration was determined by Bradford protein assay, according to the manufacturer's instructions (Bio-Rad, Hercules, CA). For immunoprecipitations, lysates were incubated with a 1:40 dilution of Ret C-19 or C-20 antibody (Santa Cruz Biotech, Dallas, TX) and immunoprecipitation matrix (Santa Cruz Biotech) at $4^{\circ} \mathrm{C}$ overnight on a rotator. A sample with no protein lysate was used as a negative control. Immunoprecipitates were pelleted and resuspended in SDS-PAGE sample buffer, and Western blot analysis was performed by incubating for 1 hour at $37^{\circ} \mathrm{C}$ with primary $\beta$-catenin antibody (BD Transduction Laboratories, Mississauga, ON, Canada) and horseradish peroxidaseconjugated secondary antibodies. The reaction was visualized using an enhanced chemiluminescence detection system (Pierce; Thermo Scientific, Rockford, IL).

\section{Statistical Analysis}

Analysis included determination of mean signal intensity and positive staining area of $G d n f$ expression in $\beta$-cat ${ }^{G O F-M M}$ mutants and wild type (WT) using NIS elements software (version AR 3.22 64-bit; Nikon). The data were analyzed using a two-tailed Student's $t$-test using GraphPad Prism 

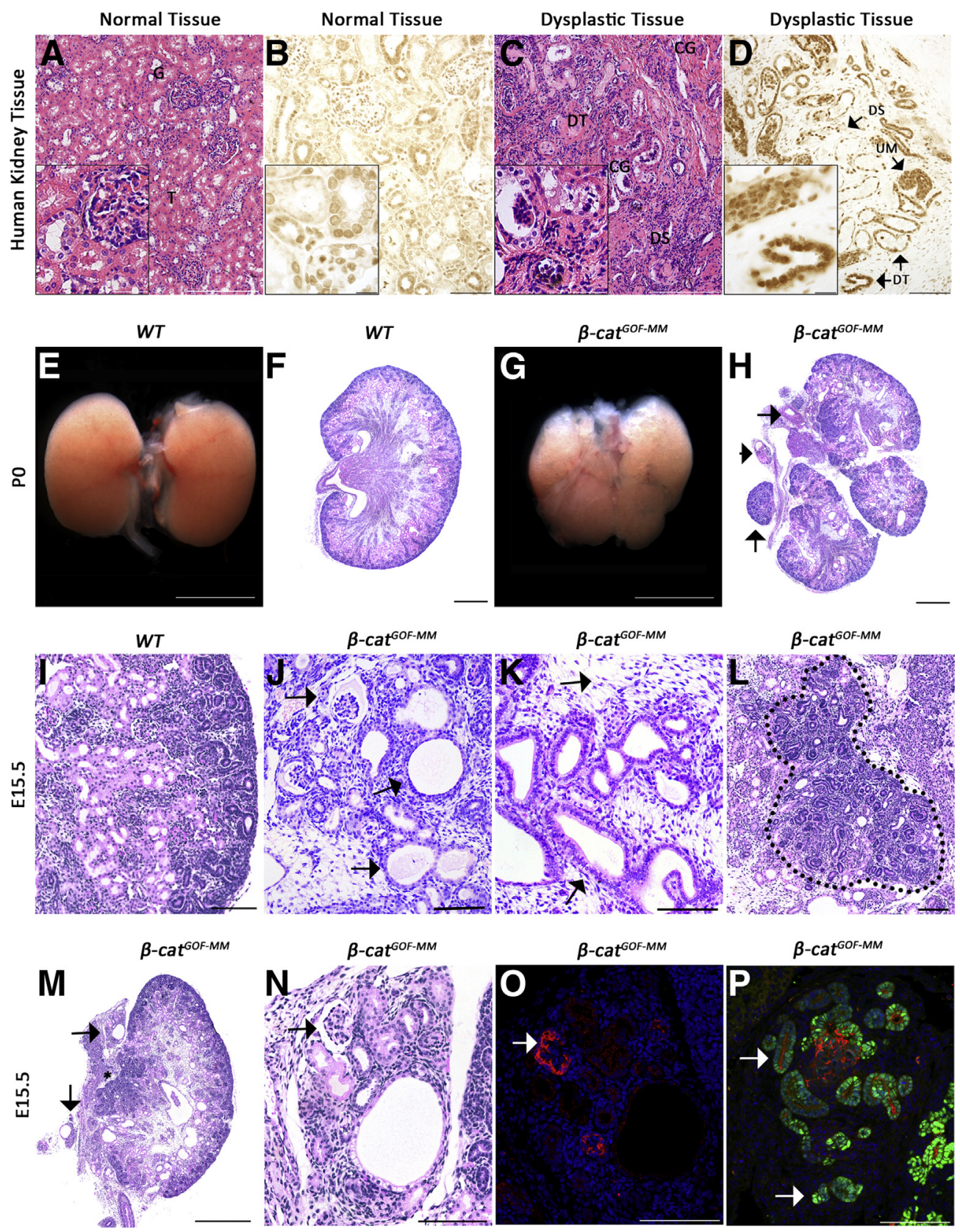

Figure 1 Elevated $\beta$-catenin levels are associated with renal dysplasia. A and C: Postnatal human kidney tissue. A: Normal human renal tissue showing glomeruli $(G)$ and tubular structures $(T)$ within the renal parenchyma [high-power image of a glomerulus and adjacent tubules (inset)]. C: Human dysplastic kidney tissue characterized by disorganized renal parenchyma, dysplastic dilated cystic tubules (DTs), cystic glomeruli (CS), and disorganized stroma (DS). B and D: IHC analysis of activated $\beta$-catenin demonstrating increased expression in the nuclei of epithelial tubules, undifferentiated mesenchyme (UM), and stroma in human renal dysplastic tissue [ $\beta$-catenin is expressed at high levels in the tubule epithelial nuclei (inset)]. $\mathbf{E}$ and $\mathbf{G}$ : Gross anatomical characteristics of WT and $\beta$-cat ${ }^{G O F-M M}$ mutant kidneys at $P=0$. In contrast to WT, $\beta$-cat ${ }^{G O F-M M}$ mutants demonstrate misshapen lobular kidneys. $\mathbf{F}$ and $\mathbf{H}$ : Histological analysis of PO kidneys reveals abnormal kidney architecture: irregular patterning of nephrogenic structures, cystic tubules, and disorganized and dilated collecting ducts in $\beta$-cat ${ }^{G O F-M M}$ mutants. In addition, $\beta$-cat ${ }^{G O F-M M}$ mutants demonstrate ectopic formation of kidney-like tissue (black arrows, high-magnification images of $\mathbf{H}$ are shown in Supplemental Figure S2, A and B). I-L: Histological analysis of E15.5 mouse kidney tissue. In contrast to WT, $\beta$-cat ${ }^{G O F-M M}$ kidney demonstrates characteristics consistent with human renal dysplasia, including multiple cystic glomeruli (black arrow: top), large cortical and medullar cysts (black arrow: bottom) (J), loosely packed stroma (black arrow: top) and undifferentiated dilated epithelial tubules (black arrow: bottom) (K), and disorganized nephrogenic zone (dotted black line) with undifferentiated mesenchyme and tubules deep into the medulla (L). M: Histological analysis of E15.5 kidneys reveals ectopic kidney-like formation in $\beta$-cat $t^{G O F-M M}$ mutants (black arrows) and undifferentiated mesenchyme penetrating deep into the medulla (asterisks). N: High-power image of ectopic kidney formation in $\beta$-cat ${ }^{G O F-M M}$ reveals the formation of mature nephrogenic structures, including glomeruli (black arrow) and other tubulogenic structures. $\mathbf{0}$ and $\mathbf{P}$ : Immunofluoresence analysis of ectopic renal tissue in $\beta$-cat ${ }^{G O F-M M}$ mutants with anti-Nephrin (red) antibody confirms the presence of glomeruli. P: Immunofluoresence with anti-Cytokeratin (red) and anti-Pax2 (green) antibody confirms the presence of ureteric (white arrow: top) and mesenchymally derived structures (white arrow: bottom). Scale bars: $200 \mu \mathrm{m}(\mathbf{A}$ and $\mathbf{C}) ; 100 \mu \mathrm{m}$ (inset, $\mathbf{A}$ and $\mathbf{C}, \mathbf{I}-\mathbf{L}$, and $\mathbf{N}-\mathbf{P}) ; 2 \mathrm{~mm}(\mathbf{E}$ and $\mathbf{G}) ; 500 \mu \mathrm{m}(\mathbf{F}, \mathbf{H}$, and $\mathbf{M})$. 
software version 5.0c (Graphpad, La Jolla, CA). $P<0.05$ was considered to indicate statistical significance. Values are given as means \pm SEM.

\section{Results}

Elevated Levels of $\beta$-Catenin Contribute to the Genesis of Renal Dysplasia

Studies have demonstrated that $\beta$-catenin is overexpressed in the ureteric epithelium in dysplastic kidneys and regulates a genetic program that results in an inhibition of branching morphogenesis, resulting in renal dysplasia. ${ }^{3}$ However, it is not known if $\beta$-catenin is overexpressed in other cell types in dysplastic human kidneys and whether this may also play a functional role in the genesis of renal dysplasia. ${ }^{3,25} \mathrm{We}$ analyzed $\beta$-catenin expression in normal (Figure 1A) and dysplastic (Figure 1C) human renal tissue using an antibody that detects the transcriptionally active form of $\beta$-catenin. In its active form, $\beta$-catenin binds to Tcf/Lef transcriptional coactivators to activate gene transcription. ${ }^{31}$ We observed low levels of activated $\beta$-catenin in the nuclei of epithelial tubules and glomeruli in normal tissue (Figure 1B). In contrast, activated $\beta$-catenin was highly expressed in the nuclei of dysplastic epithelium, dilated and cystic epithelial tubules, stromal cells, and regions of undifferentiated mesenchyme (Figure 1D). Next, we wanted to determine the functional significance of $\beta$-catenin overexpression in the mesenchyme and its daughter tissue elements. By using the Cre-LoxP system, we crossed Rarß2-Cre driver mice with mice containing a floxed exon 3 of the $\beta$-catenin allele to generate mice that overexpress $\beta$-catenin exclusively in the metanephric mesenchyme. This cross results in the deletion of essential phosphorylation sites that are necessary for $\beta$ catenin degradation. ${ }^{26,32}$ Thus, $\beta$-catenin accumulates in the cytoplasm and is shuttled to the nucleus of mesenchymal cells, mimicking the $\beta$-catenin overexpression observed in human dysplastic tissue (Supplemental Figure S1). These mutant mice, termed $\beta$-catenin gain-of-function metanephric mesenchyme $\left(\beta-c a t^{G O F-M M}\right)$, died within hours of birth and kidney tissue was immediately isolated for histological analysis. In contrast to WT, $\beta$-cat ${ }^{G O F-M M}$ mutants demonstrated bilateral misshapen lobular kidneys with dilated ureters and disorganized cortical and medullary patterning (Figure 1, E-H, and Supplemental Figure S2). Histological analysis of $\beta$-cat ${ }^{G O F-M M}$ during the embryonic stage (E) 15.5 revealed multiple large cysts in the cortical and medullary epithelium, cystic glomeruli (Figure 1J), undifferentiated dilated epithelial tubules surrounded by loosely arranged stroma (Figure 1K), and zones of undifferentiated mesenchyme penetrating into the deep medulla (Figure 1, $\mathrm{L}$ and $\mathrm{M}$ ). These features are remarkably similar to the histopathological morphological characteristics observed in human dysplastic renal tissue. ${ }^{1,4,6}$ These results support a functional role for mesenchymal overexpression of $\beta$-catenin in the genesis of renal dysplasia.
In addition to the histopathological changes consistent with human renal dysplasia, we observed two large kidneys per animal with two to three rudimentary kidney-like structures around their periphery for a total of six to eight kidneys per $\beta$-cat ${ }^{G O F-M M}$ mouse (Figure 1, M-P). Examination of these kidney-like structures by histological and immunofluorescence studies demonstrated Nephrin-, Pax2-, and Cytokeratin-positive structures (Figure 1, N-P), confirming that they are small kidneys containing one to two nephrons.

\section{$\beta$-cat ${ }^{\text {GOF-MM }}$ Mice Display Disorganized Nephrogenic}

\section{Structures}

The histopathological changes observed in $\beta$-cat ${ }^{\text {GOF-MM }}$ mice prompted us to investigate whether key developmental processes that guide kidney development were disrupted. Because we observed zones of undifferentiated mesenchyme in post-natal kidneys, we suspected alterations in nephrogenesis could contribute to the dysplastic phenotype. During normal kidney development, the newly forming nephrons are limited to the outer cortex in a region termed the nephrogenic zone. We analyzed the nephrogenic zone for developing and maturing nephrogenic structures using the markers Six2, Pax2, and Wt-1 for the nephrogenic progenitor population, the induced mesenchyme, and the developing podocytes, respectively. Our results revealed that the nephrogenic zone in $\beta$-cat ${ }^{G O F-M M}$ was comparable to WT with respect to the expression of common nephrogenic proteins (Figure 2, A-F). This suggested that the nephrogenic program remained intact and was likely not a major contributor to our dysplastic phenotype. However, the mesenchymal progenitor population, induced mesenchyme, and developing glomeruli demonstrated sporadic regions in which the nephrogenic structures expanded outside of the nephrogenic zone deep into the medulla of $\beta$-cat ${ }^{G O F-M M}$ mutant kidneys, which was never observed in WT kidneys (Figure 2, G-L). Taken together, these studies observationally demonstrate that $\beta$ cat ${ }^{G O F-M M}$ mutants can initiate and complete the nephrogenic program, but also display focal zones of stalled nephrogenic structures penetrating deep into the renal medulla (a common characteristic of human renal dysplasia).

\section{Ectopic and Disorganized Branching Morphogenesis in} $\beta$-cat ${ }^{\text {GOF-MM }}$ Mice

Alterations in branching morphogenesis could account for the irregular pattern of induced mesenchyme structures within the medulla and ectopic ureteric epithelium in the rudimentary ectopic kidneys. Thus, we investigated the functional contribution of $\beta$-catenin overexpression in the metanephric mesenchyme on branching morphogenesis by performing whole-mount immunofluorescence using the antibody Cytokeratin, a specific marker of the ureteric epithelia. The ureteric bud invaded the metanephric mesenchyme and generated a normal bifid branch in WT and $\beta$-cat ${ }^{G O F-M M}$ mutant kidneys at E11.5 (Figure 3, A and 
E). However, we did observe a minimum of one extra ureteric bud arising off the Wolffian duct in four of six mutants analyzed at E11.5 (Figure 3E). The analysis of ureteric branch patterning at E12.5 and E13.5 revealed severely disorganized ureteric branch patterning and ectopic budding off the ureteric stalk and Wolffian duct in $\beta$-cat ${ }^{G O F-M M}$ mutant kidneys (Figure 3, B and $\mathrm{C}$ versus $\mathrm{F}-\mathrm{H})$. In addition, the number of ureteric branch generations was significantly reduced when compared with controls. Interestingly, we also observed numerous Cytokeratinpositive structures around the periphery of the ureteric tree that appeared disconnected from the existing ureteric branches or the Wolffian duct (Figure 3, G and H). Taken together, these results demonstrate that overexpression of $\beta$-catenin in the metanephric mesenchyme results in ectopic disorganized ureteric budding and branching morphogenesis.

\section{Gdnf Expression Is Transcriptionally Regulated by $\beta$-Catenin}

Gdnf, Ret, and Wnt11 are essential regulators of ureteric budding, branching, and patterning, respectively. ${ }^{9,10,33}$ To begin to define a molecular mechanism that mediates $\beta$-catenin-dependent changes in ureteric budding and branching, we first examined Gdnf expression by in situ hybridization. The intensity of $G d n f$ expression and the spatial domain of $G d n f$ in the metanephric mesenchyme of $\beta$-cat ${ }^{G O F-M M}$ mutants were markedly increased when
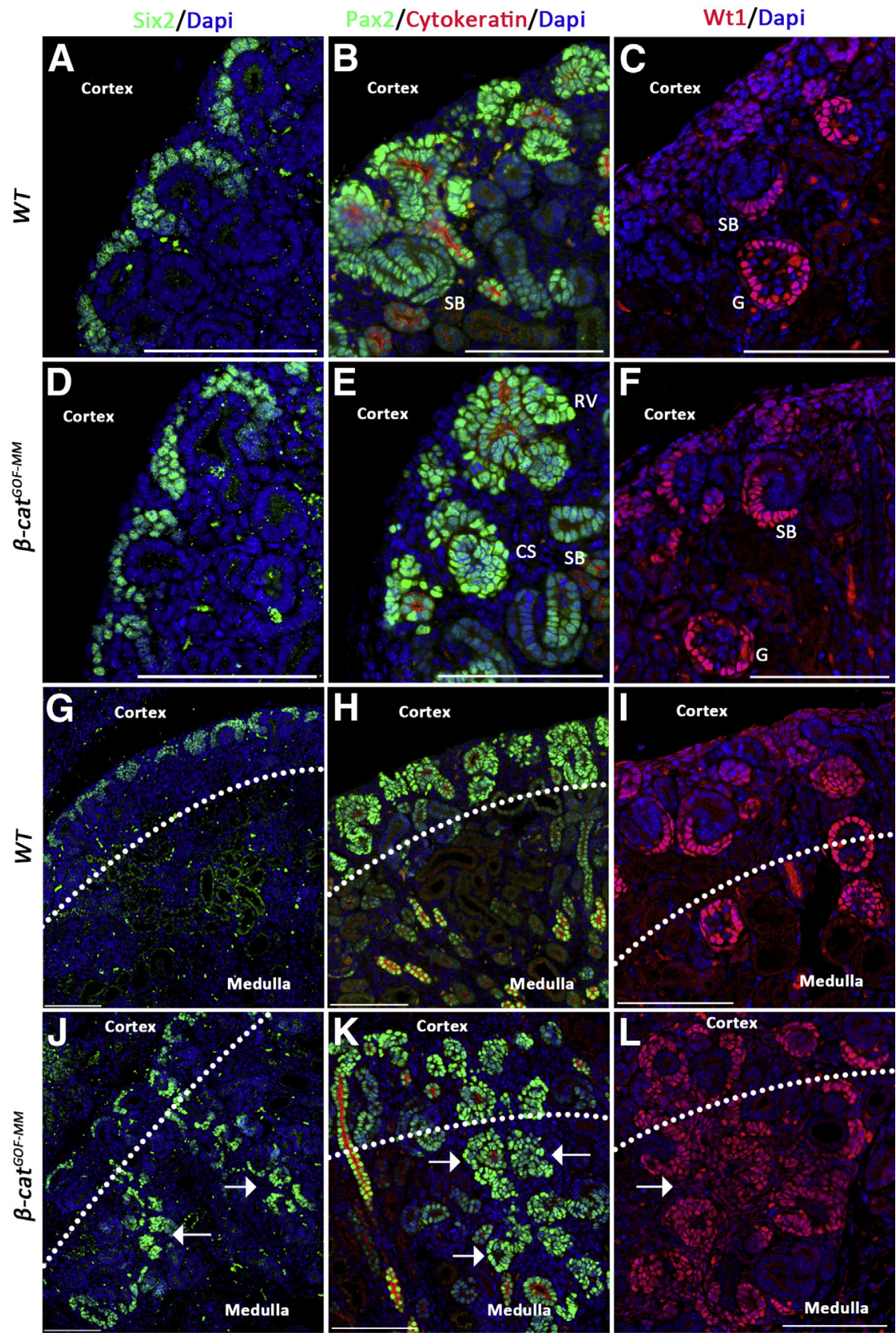

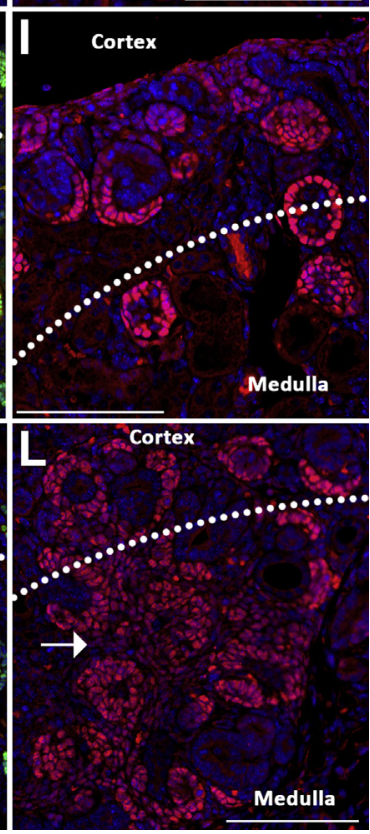

Figure $2 \beta$-Cat ${ }^{G O F-m m}$ mutants display normal nephrogenesis and sporadic zones of disorganized nephrogenic structures. A-F: Analysis of the cortical region in WT and $\beta$-cat ${ }^{G O F-M M}$ kidney tissue at E15.5 using immunofluoresence microscopy (DAPI marks nuclei blue). A and D: Analysis of the Six2 nephron progenitor population using antiSix2 (green) antibody demonstrates similar expression patterns in WT and $\beta$-cat ${ }^{G O F-M M}$ kidneys. $\mathbf{B}$ and $\mathbf{E}$ : Analysis of the cortical region using antiPax2 (green) antibody and anti-Cytokeratin (red) antibody demonstrates the condensing mesenchyme, the formation of renal vesicle (RV), comma-shaped bodies (CSs), and s-shaped bodies (SBs) in $\beta$-cat ${ }^{G O F-m m}$ kidneys. C and F: Analysis of developing glomeruli in WT and $\beta$-cat ${ }^{\text {GOF-MM }}$ kidneys using anti-Wt1 (red) antibody demonstrates similar expression patterns in developing glomeruli (SB) and mature glomeruli $(\mathrm{G})$ in both WT and $\beta$-cat ${ }^{G O F-M M}$ kidneys. G-L: Analysis of the cortical and medullary regions of $\beta$-cat ${ }^{G O F-M M}$ and WT tissue at E15.5 using immunofluoresence microscopy (DAPI marks nuclei blue). G and J: $\beta$-Cat ${ }^{\text {GOF-mm }}$ mutants demonstrate a disorganization of the mesenchyme progenitor population into the medulla (white arrows). $\mathbf{H}$ and K: $\beta$-Cat ${ }^{G O F-M M}$ mutants demonstrate nephrogenic structures and ureteric duct tips into the medulla (white arrow). I and L: Analysis of developing and mature podocytes displays a disorganized expression pattern and medullary expansion in $\beta$-cat ${ }^{G O F-M M}$ mutants. Scale bar $=100 \mu \mathrm{m}(\mathbf{A}-\mathbf{L})$. 
compared with WT controls (Figure 3, I, L, O, and P). Because Gdnf acts within a Gdnf-Ret-Wnt11-positive autoregulatory feedback loop, we also analyzed the expression of Ret and Wnt11. As expected, Ret was expanded in the ureteric tip and stalk when compared with WT (Figure 3, J and M), and Wnt11 demonstrated a similar expression pattern as WT, but the visual intensity at the ureteric tips was increased in $\beta$-cat ${ }^{G O F-M M}$ kidneys
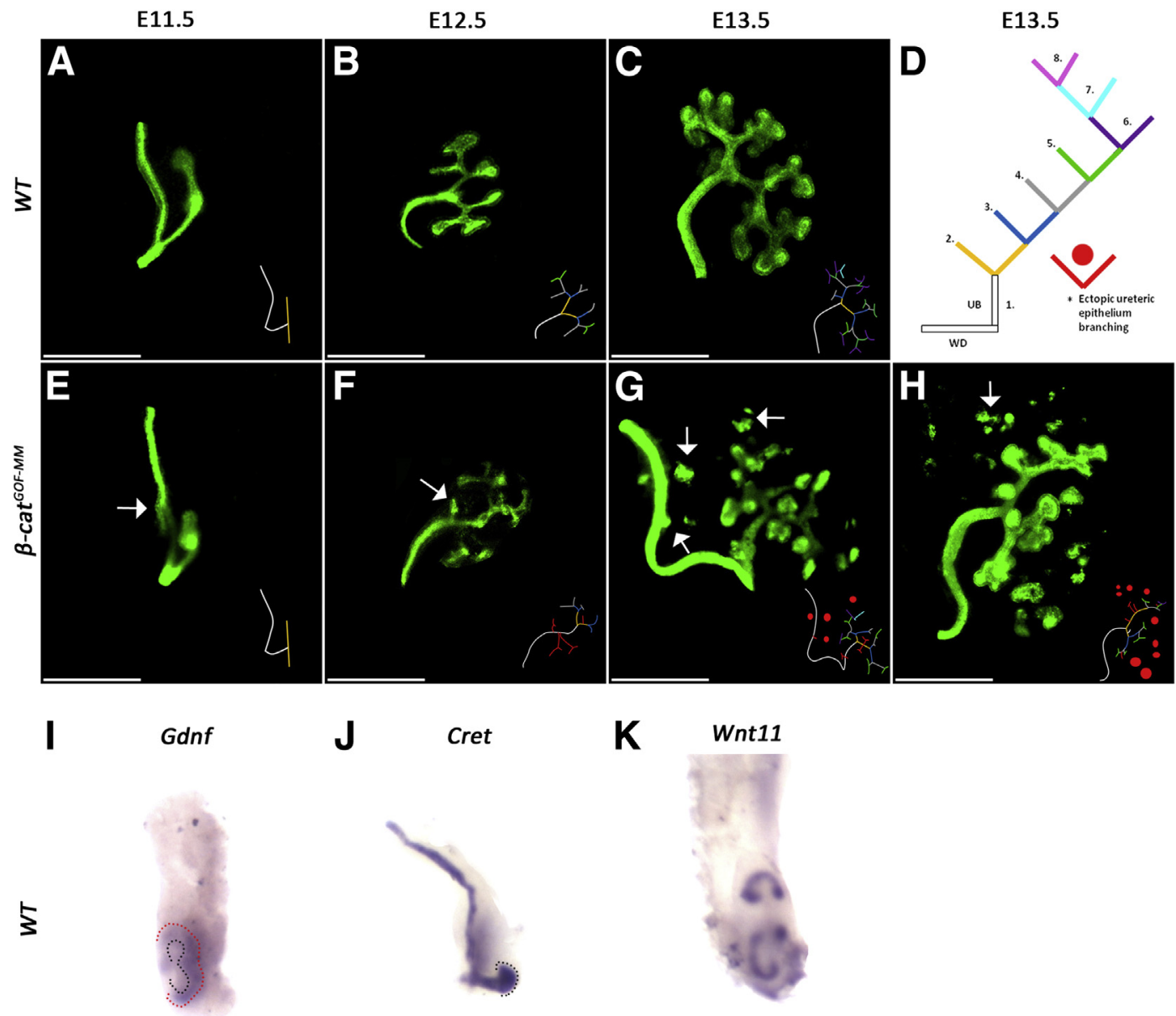

J cret
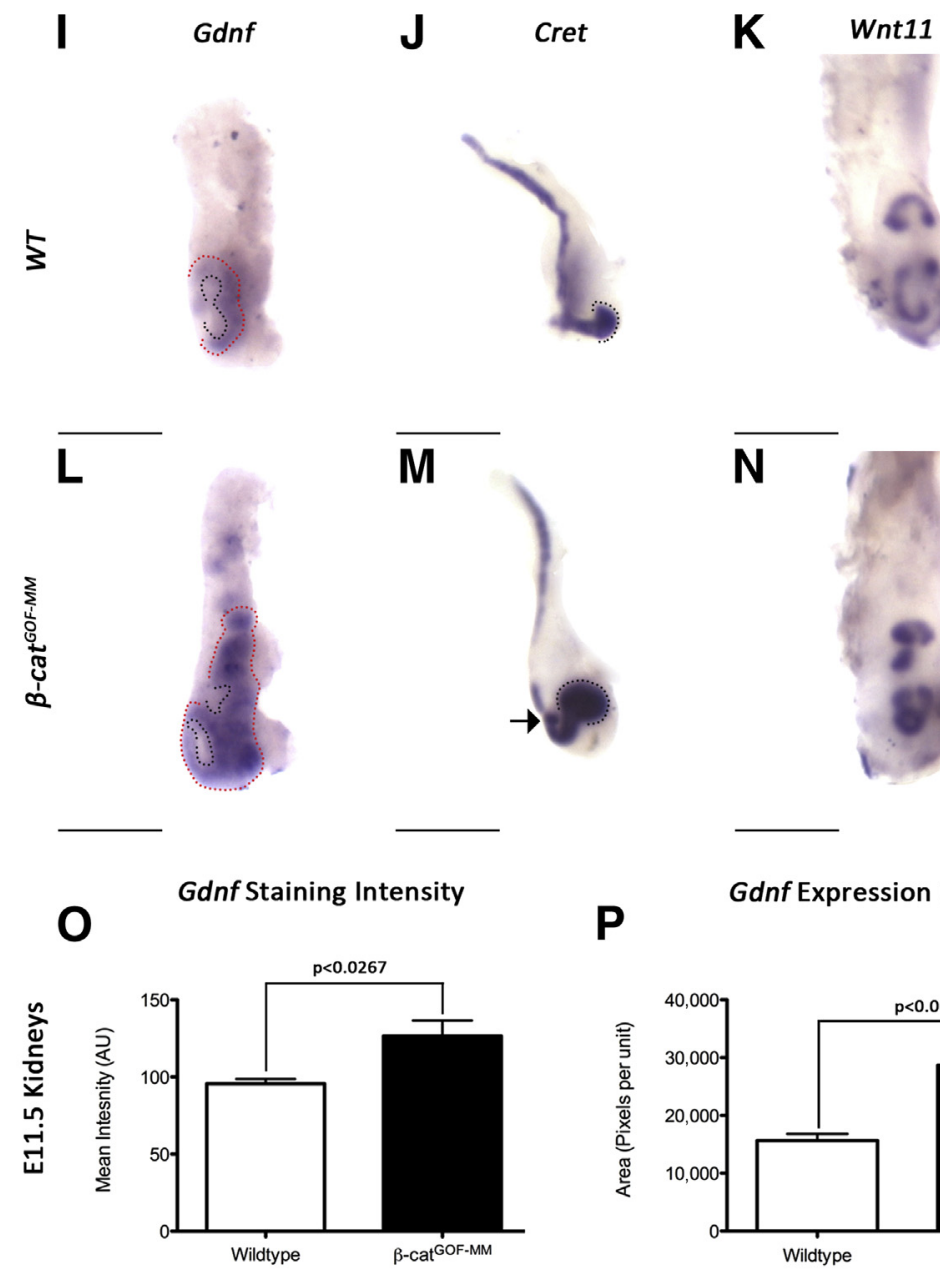

$\mathbf{P}$

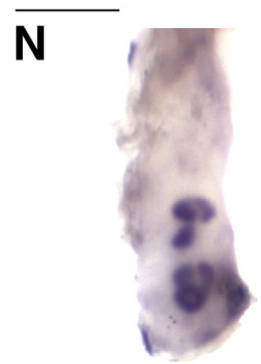

Gdnf Expression Domain

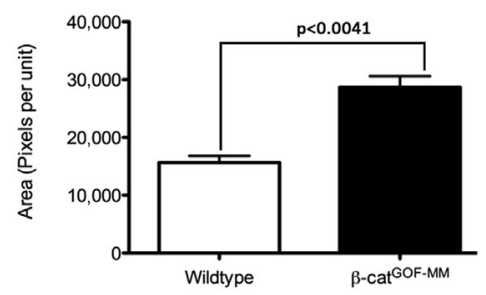


(Figure 3, $\mathrm{K}$ and N). Taken together, $\beta$-cat ${ }^{G O F-M M}$ mutants exhibit alterations in the key molecular pathway that controls ureteric budding and branching morphogenesis.

We hypothesized that the etiology of the ureteric branching defects resulted from alterations in $G d n f$ expression, likely caused by $\beta$-catenin-dependent regulation of Gdnf. To support this hypothesis, we genetically deleted $\beta$-catenin from the metanephric mesenchyme $\left(\beta-c a t^{L O F-M M}\right)^{28}$ and demonstrated that $\beta$-cat $t^{L O F-M M}$ mutant kidneys were hypodysplastic, lacked proper kidney patterning at $P=0$, and demonstrated markedly reduced ureteric branching (Figure 4, A and B, and Supplemental Figure S3), phenotypes consistent with a reduction of $G d n f$ expression. Analysis of $G d n f$ mRNA expression at E11.5 revealed a marked reduction, most notably in the region surrounding the ureteric tips in $\beta$-cat ${ }^{L O F-M M}$ kidneys (Figure 4, C and D). The intensity of Ret and Wnt11 expression was similar to WT; however, Ret expression was not fully limited to the tips of the branching ureteric bud in $\beta$-cat ${ }^{L O F-M M}$ mutants (Supplemental Figure S4). Taken together, these findings strongly suggest that $\beta$ catenin controls $G d n f$ expression.

Previous in vitro studies have demonstrated that stimulation of the canonical Wnt-signaling pathway leads to elevations in $G d n f$ expression, ${ }^{34,35}$ yet it is not clear whether $\beta$-catenin directly binds to the proximal promoter of $G d n f .{ }^{35}$ We performed ChIP on E13.5 kidney tissue lysates and demonstrated that $\beta$-catenin does interact with three Tcf/Lef consensus binding sites located 4.9, 2.25, and $2.1 \mathrm{~kb}$ upstream of the Gdnf transcriptional start site (Figure 4E). We performed quantitative RT-PCR, which showed that the 4.9- and 2.25-kb consensus sites had the highest enrichment (Figure 4E). To determine whether $\beta$ catenin regulated gene transcription in the Gdnf promoter, we subcloned the $4.9-\mathrm{kb}$ consensus binding site upstream of a luciferase gene and transfected the construct into HEK293 cells. The luciferase activity was significantly increased when cells were stimulated with $\mathrm{LiCl}$ or Wnt3A (data not shown), activators of the $\beta$-catenin-mediated signaling pathway $(P<0.0135)$ (Figure $4 \mathrm{~F})$. These studies demonstrate that $\beta$-catenin binds to the Tcf/Lef sites in the Gdnf promoter and can directly regulate its transcription in vitro.
Our results suggest that the increase in $\beta$-catenin causes an increase in Gdnf, resulting in altered branching and renal dysplasia. Therefore, $\beta$-cat ${ }^{G O F-M M}$ kidney explants cultured in the presence of neutralizing Gdnf antibodies should result in a restoration of normal branching phenotype. E11.5 $\beta$-cat ${ }^{G O F-M M}$ kidney explants were cultured in the absence of neutralizing Gdnf antibodies, which demonstrated the development of ectopic kidneys with a normal $\mathrm{t}$-shaped branch that did not progress beyond one or two branch generations (Figure $4 \mathrm{G}$ ). $\beta$-cat ${ }^{G O F-M M}$ mutant kidneys cultured in the presence of Gdnfneutralizing antibodies partially restored the branching phenotype because branching progressed beyond two branch generations (Figure $4 \mathrm{H}$ ) and the ectopic kidneys were not observed. As a control, WT kidney explants were also cultured in the presence and absence of Gdnfneutralizing antibodies (Supplemental Figure S5). These studies indicate that neutralizing the effects of Gdnf partially rescued the branching phenotype in $\beta$-cat ${ }^{G O F-M M}$ mutants, demonstrating the important role for Gdnf in the genesis of our dysplastic phenotype.

\section{A Novel Ret/ $\beta$-Catenin-Mediated Signaling Pathway in Kidney Development and Disease}

In addition to ectopic ureteric budding and disorganized branch patterning, we also observed marked reductions in the number of ureteric branch generations in $\beta$-cat ${ }^{G O F-M M}$ mutants, suggesting additional mechanisms may inhibit ureteric branching in these mice. Our previous work demonstrated that $\beta$-catenin overexpression exclusively in the ureteric tissue resulted in a phenotype characterized by disorganized branching that rarely progressed beyond the initial T-shaped branch at E11.5, ${ }^{25}$ a phenotype similar to what we observed in cultured $\beta$-cat ${ }^{G O F-M M}$ kidney explants. Studies by Gujral et $\mathrm{al}^{36}$ identified a novel $\mathrm{Ret} / \beta$-catenin-mediated signaling pathway involved in the development of thyroid carcinoma. Therefore, we investigated whether the Ret/ $\beta$-catenin-mediated signaling pathway plays a functional role in $\beta$-catenin activity in the ureteric epithelium. Initially, we investigated whether Ret and $\beta$ catenin interacted with E14.5 kidney tissue lysates by performing immunoprecipitation with Ret antibodies and

\footnotetext{
Figure $3 \quad \beta$-cat ${ }^{G O F-M M}$ mutants demonstrate ectopic and abnormal branching morphogenesis and increased Gdnf, Ret, and Wnt11. A-H: Whole-mount immunofluoresence using anti-Cytokeratin antibody to mark the ureteric bud (white arrow indicates ectopic ureteric budding. D: Line diagram using a color code to represent branch generation. The primary bud from the Wolffian duct is considered the first generation (white); the first two branches that form from the primary bud are the second generation (yellow). Red line represents ectopic branching morphogenesis. A and E: $\beta$-cat ${ }^{G O F-M M}$ mutant displays ectopic branching of the Wolffian duct and a normal T branch at E11.5. B and F: In contrast to WT, $\beta$-cat ${ }^{G O F-M M}$ mutant displays ectopic branching off the initial ureteric stalk and disorganized and limited branching morphogenesis at E12.5. C, G, and H: Analysis of branching morphogenesis at E13.5 reveals an ectopic ureteric bud growth, disorganized branching morphogenesis, and ectopic Cytokeratin-positive structures outside the developing collecting duct system in $\beta$-cat ${ }^{G O F-M M}$ mutants. I-N: Whole-mount in situ hybridization for Gdnf, Ret, and Wnt11 in E11.5 WT and $\beta$-cat ${ }^{G O F-M M}$ kidneys (black dotted line indicates ureteric bud). I and L: In contrast to WT, Gdnf expression levels were higher on the basis of staining intensity and encompassed a larger domain (red dotted line) in $\beta$-cat ${ }^{G O F-M M}$ kidney. $\mathbf{J}$ and $\mathbf{M}$ : In contrast to the WT, Ret expression is expanded in the ureteric bud tip and stalk of $\beta$-cat ${ }^{G O F-M M}$ kidney. $\mathbf{K}$ and $\mathbf{N}$ : Wnt11 is expressed in the tips of the ureteric epithelium at higher levels on the basis of staining intensity in $\beta$-cat ${ }^{G O F-M M}$ kidneys. $\mathbf{0}$ and P: Quantification of Gdnf staining intensity (WT versus $\beta$-cat ${ }^{G O F-M M}$ mean, 95.68 versus 126.5 arbitrary units; $P<0.0267$ ) and $G d n f$ expression domain (WT versus $\beta$-cat ${ }^{G O F-M M}$ mean, 15,660 versus 28,700 arbitrary units; $P<0.0041$ ) demonstrates significantly increased Gdnf expression in $\beta$-cat ${ }^{G O F-M M}$ mutants. Staining intensity and expression domain were calculated using NIS elements software (version AR 3.22 64-bit; Nikon). Scale bar $=250 \mu \mathrm{m}(\mathbf{A}-\mathbf{N})$.
} 
immunoblotting for $\beta$-catenin. Our results revealed $\beta$-catenin could be readily detected after immunoprecipitation with Ret in embryonic kidneys (Figure 5A). To determine the effects of the Ret/ $\beta$-catenin interaction on Ret receptor activation, kidney explants were cultured in the presence or
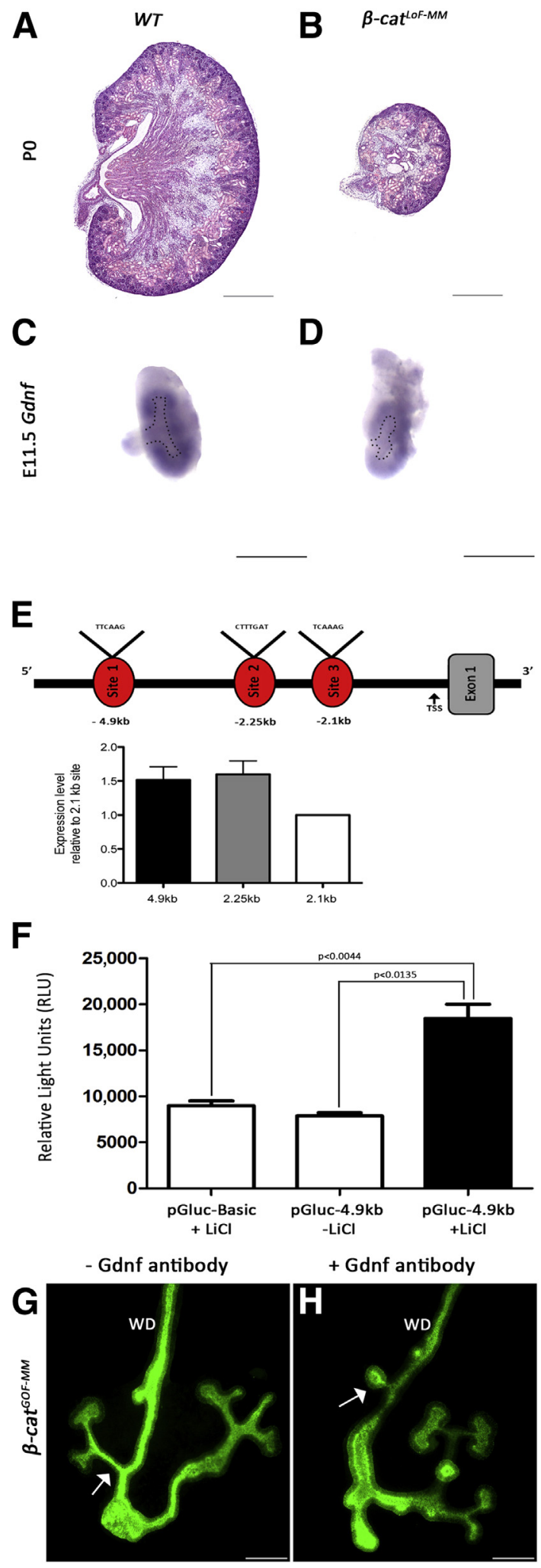

absence of Gdnf. Immunoprecipitation of Ret, followed by immunoblotting for $\beta$-catenin, demonstrated reduced Ret $/ \beta$ catenin molecular complexes in Gdnf-stimulated samples $(P<0.0063)$, suggesting that $\beta$-catenin is released from the Ret receptor upon Gdnf stimulation (Figure 5B). Furthermore, kidneys isolated from WT;Tcf reporter mice, which contain multiple Tcf consensus binding sites upstream of a $\beta$-galactosidase gene, cultured in the presence of Gdnf demonstrated markedly increased Tcf activity within the ureteric epithelium (Figure 5, C and E). Furthermore, kidney explants demonstrated increased cytoplasmic and nuclear $\beta$ catenin localization with Gdnf stimulation (Figure 5, D and F). These studies demonstrate that Ret stimulation with Gdnf activates $\beta$-catenin-mediated intracellular signaling. Remarkably, $\beta$-cat ${ }^{G O F-M M}$ mutants that contained Tcf sites linked to a $\beta$-galactosidase reporter gene (Tcf/LacZ; $\beta$-cat ${ }^{G O F-M M}$ mice) demonstrated a marked increase in reporter activity in the ureteric epithelium compared with WT (Figure 5, G and H). These studies implicate the presence of a novel intracellular signaling pathway in kidney development and suggest an additional pathological hit in which increased $\beta$-catenin in the metanephric mesenchyme also leads to increased $\beta$-catenin activity in the ureteric epithelium. As demonstrated in our previous report, increased $\beta$-catenin activity within the ureteric epithelium has inhibitory effects on branching morphogenesis, ${ }^{25}$ consequently further exacerbating the disorganized branching phenotype observed in $\beta$-cat ${ }^{G O F-M M}$ mutants.

\section{GDNF Is Up-Regulated in Human Dysplastic Renal Tissue}

By using our $\beta$-cat ${ }^{G O F-M M}$ mutant mouse model, we have identified a novel mechanism in the genesis of renal dysplasia. To determine whether this mechanism is translated to human kidney pathological characteristics, we analyzed dysplastic

\footnotetext{
Figure $4 \quad \beta$-Catenin directly regulates $G d n f$ expression. A and B: Histological analysis of newborn kidneys reveals renal hypodysplasia in $\beta$-cat ${ }^{\text {LOF-MM }}$ mutants (high-magnification images of $\mathbf{B}$ are shown in Supplemental Figure S5, C and D). C and D: Whole-mount in situ hybridization for Gdnf; in contrast to WT, the intensity of Gdnf expression levels is lower in $\beta$-cat ${ }^{L O F-M M}$ kidney (dotted line indicates ureteric bud). E: The position and sequence of the conserved Tcf/Lef transcription factor binding sites in the Gdnf promoter region are shown. ChIP of E14.5 kidney lysates, followed by quantitative RT-PCR of 4.9-, 2.25-, and 2.1-kb fragments. Graph shows the expression levels of the $4.9-$ and $2.25-\mathrm{kb}$ consensus binding sites. F: The $4.9-\mathrm{kb}$ fragment was cloned upstream of a luciferase reporter gene and transfected into HEK293 cells. HEK293 cells stimulated with $\mathrm{LiCl}$ demonstrated a marked increase in light emission compared with HEK293 cells with no treatment $(P<0.0135)$. $\mathbf{G}$ and $\mathbf{H}$ : Whole-mount immunofluoresence using anti-Cytokeratin antibody. G: E11.5 $\beta$-cat ${ }^{G O F-M M}$ mutant kidneys were cultured for 2 days in control media and demonstrated the formation of an ectopic branching ureteric bud (white arrow). H: $\beta$-Cat ${ }^{G O F-M M}$ mutant kidneys cultured for 2 days in $10 \mu \mathrm{g} / \mathrm{mL}$ of anti-Gdnfneutralizing antibody demonstrate lack of formation of an ectopic branching ureteric bud (white arrow) and demonstrated increased branch generations. Scale bars: $500 \mu \mathrm{m}$ (A and B); $250 \mu \mathrm{m}$ (C and D). TSS, transcriptional start site; WD, Wolffian duct.
} 
kidney tissue for changes in GDNF expression. We initially performed IHC on serial sections using antibodies against PAX2 (Figure 6, A and D) and anti-active $\beta$-catenin (Figure 6, $\mathrm{B}$ and $\mathrm{E}$ ) to identify a population of metanephric mesenchyme cells and determine whether the activated form of $\beta$-catenin was also expressed in the same subset of cells. Indeed, the population of cells expressing PAX2 also demonstrated the activated form of $\beta$-catenin (Figure 6, B and E). Interestingly, serially sectioned postnatal human dysplastic kidney tissue that demonstrated positive immunoreactivity with antibodies to activated $\beta$-catenin also expressed GDNF, which is never observed in normal postnatal kidney tissue (Figure 6, C and F). Furthermore, a unique aspect of our mouse model of renal dysplasia is that we observed three to four ectopic kidneys in $\beta$-cat ${ }^{G O F-M M}$ mutants. Remarkably, we also observed small rudimentary kidneys in human dysplastic kidney tissue isolated from a 38-week-old fetus, suggesting this phenomenon also occurs during human renal dysplasia (Figure 6G). The analysis of dysplastic kidney tissue from a 38-week-old fetus also demonstrated GDNF expression around the cytokeratinpositive ureteric epithelium (Figure 6, H and I). The expression pattern is consistent with its role as a secreted factor from the surrounding mesenchyme and binding to its receptor located on the ureteric epithelium (Figure 6I). Interestingly, these ureteric-derived tubules exhibited high levels of activated $\beta$-catenin (Figure $6 \mathrm{~J}$ ), supporting our findings in $\beta$-cat ${ }^{G O F-M M}$ mice. These studies emphasize that the mechanisms observed in our $\beta$-cat ${ }^{G O F-M M}$ mice are likely occurring in human dysplastic kidneys.

\section{Discussion}

Renal dysplasia is defined by varying degrees of abnormal development of the kidney. The histopathological characteristics in renal dysplasia are characterized by cystic tubules, inhibition of mesenchyme and ureteric epithelium differentiation, fibrosis, and duplicate collecting systems. The dysplastic renal tissue can be focally localized or affect the entire kidney. Although changes in gene expression in dysplastic kidney tissue have been demonstrated, the molecular mechanisms governing the genesis of renal dysplasia remain poorly defined. Herein, we demonstrate that the transcriptional co-activator $\beta$-catenin is overexpressed in the ureteric bud, renal stroma, and metanephric mesenchyme, in human dysplastic renal tissue. By overexpressing $\beta$-catenin exclusively in mouse kidney mesenchyme, we were able to recapitulate the histopathological changes observed in human renal dysplasia. The molecular characterization of the mutant mice demonstrated increased Gdnf expression, which disrupted ureteric budding and branch patterning and, interestingly, stimulated a novel Ret/ $\beta$-catenin-mediated signaling pathway within the ureteric epithelium, which inhibited branch generation. The importance of Gdnf to the dysplastic phenotype was further demonstrated by reducing Gdnf levels that partially recovered the dysplastic phenotype in our mutants. Finally, analysis of human fetal and postnatal dysplastic
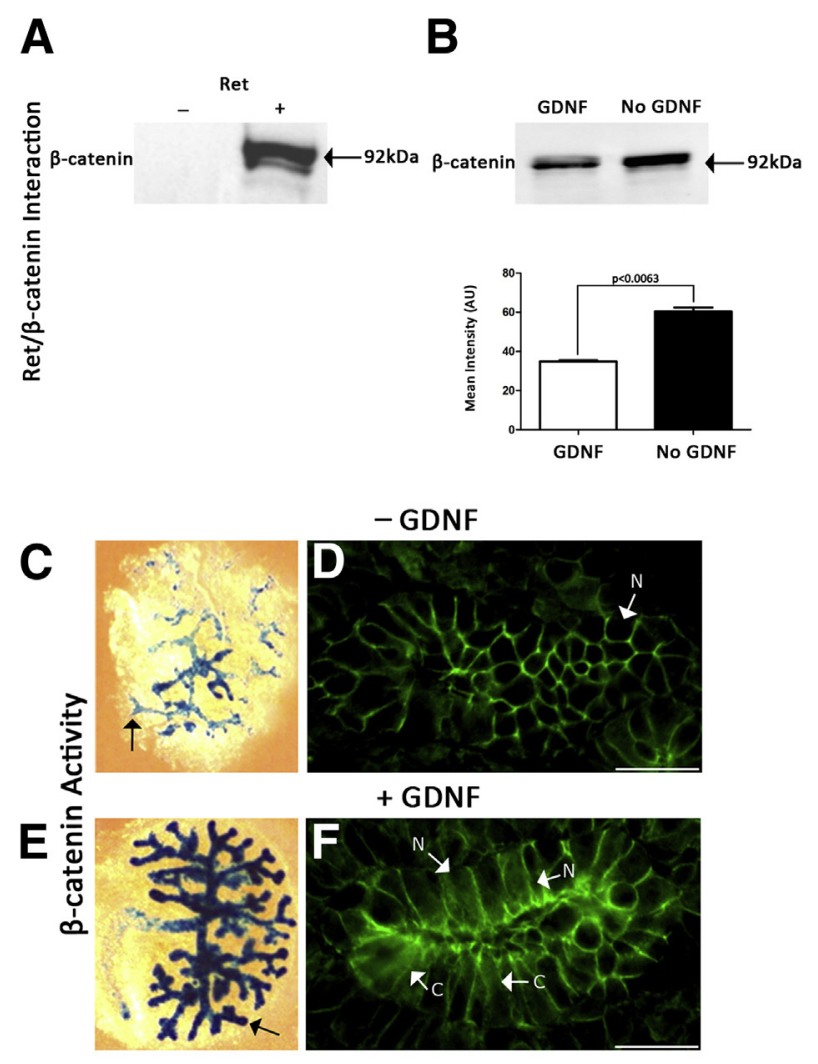

G

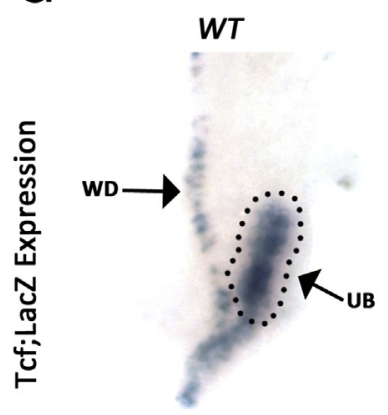

H

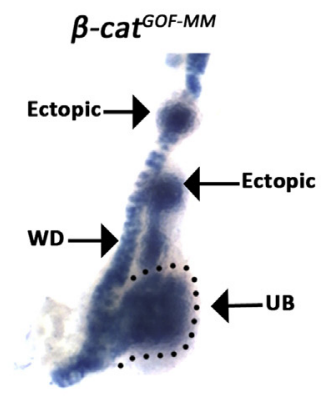

Figure 5 Identification of a novel Ret/ $\beta$-catenin-mediated signaling pathway in the developing kidney. A: Ret and $\beta$-catenin interact directly. Protein isolates from WT kidneys (E14.5) were immunoprecipitated with an anti-Ret antibody. Subsequent Western blot analysis for $\beta$-catenin demonstrates the presence of Ret- $\beta$-catenin complexes. B: Co-immunoprecipitation for Ret and $\beta$-catenin was performed on protein isolated from Gdnf-stimulated and unstimulated E14.5 murine kidneys. Lower levels of $\beta$-catenin-Ret complexes were found in the Gdnfstimulated versus unstimulated samples $(P<0.0063)$, and staining intensity was quantified using NIS elements software (version AR 3.22 64-bit; Nikon). C and E: Whole-mount X-Gal staining in E14.5 WT Tcf reporter mice. Kidneys treated with Gdnf demonstrate increased Tcf reporter activity within the ureteric epithelium (black arrow). D and F: Immunofluorescence using anti-active $\beta$-catenin demonstrates increased cytoplasmic $(\mathrm{C})$ and nuclear $(\mathrm{N})$ localization in the ureteric epithelium when treated with Gdnf. G and H: Whole-mount X-Gal staining in E11.5 kidneys isolated from WT Tcf reporter mice and $T c f / l a c Z ; \beta$-cat ${ }^{G O F-M M}$ mutants. X-Gal staining in $\beta$-cat ${ }^{G O F-M M}$ mutants is noticeably increased compared with WT littermates. UB, ureteric epithelium; WD, Wolffian duct. Scale bar $=20 \mu \mathrm{m}$ (D and $\mathbf{F})$. 
tissue compliments the mechanism we defined in our mutant mouse model. Combined, these studies highlight a critical cell autonomous and nonautonomous function for $\beta$-catenin in the genesis of renal dysplasia.

The misexpression of numerous growth factors, signaling pathways, and transcription factors has been observed in human and mouse models of renal dysplasia. ${ }^{25,37,38}$ Although previous reports demonstrated that $\beta$-catenin is overexpressed in ureteric bud-derived cysts within dysplastic human renal tissue, ${ }^{3}$ our studies extend these findings by spatially localizing $\beta$-catenin overexpression to the metanephric mesenchyme and renal stroma in dysplastic human renal tissue. Furthermore, in its activated form, $\beta$-catenin translocates to the nucleus, where it interacts with members of the Tcf/lef family of DNA-bound transcription factors to activate gene transcription. We used an antibody that specifically detects the activated form of $\beta$-catenin and demonstrated that it is overexpressed in the nuclei of ureteric, mesenchymal, and stromal cells. These studies suggest that $\beta$-catenin may play important roles in the regulation of key genes responsible in the pathogenesis of renal dysplasia.

It is well established that Gdnf is an essential regulator of ureteric budding and branching and ectopic expression of Gdnf induces the formation of ectopic ureteric buds and disorganized ureteric branch patterning, ${ }^{39-41}$ a phenotype similar to our mutant mice. Thus, we initially focused on the expression of $G d n f$ in $\beta$-cat ${ }^{G O F-M M}$ mutants and observed that $G d n f$ was significantly overexpressed in $\beta$-cat ${ }^{G O F-M M}$ mice, whereas it was noticeably reduced in $\beta$-cat ${ }^{L O F-M M}$ mutants, strongly suggesting that $\beta$-catenin regulated $G d n f$. By performing ChIP analysis on embryonic kidneys, we determined that $\beta$-catenin does bind to three Tcf/lef consensus binding sites within the initial $5 \mathrm{~kb}$ of the $G d n f$ promoter. By molecularly cloning the 4.9-kb Tcf/lef

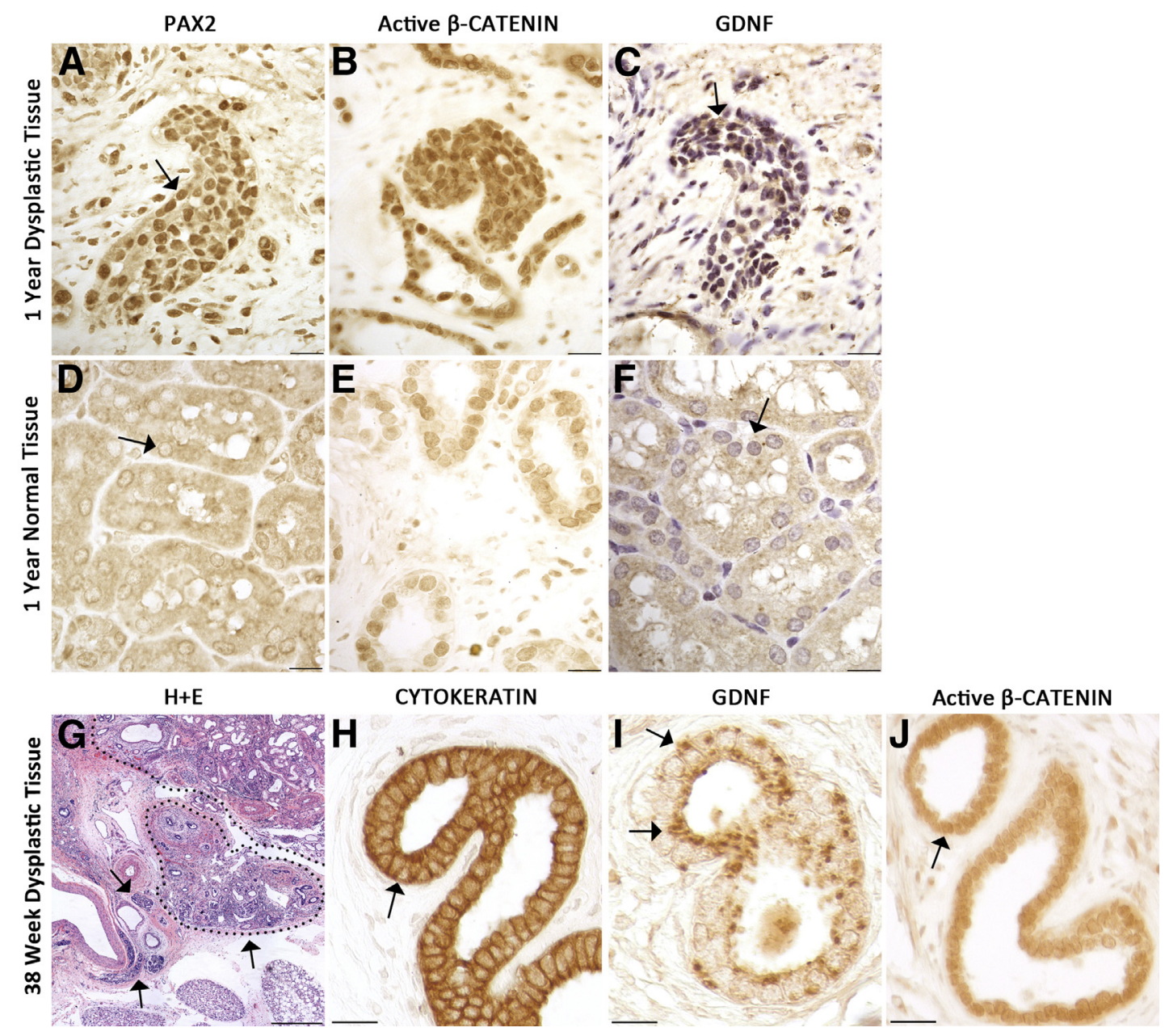

Figure 6 GDNF is up-regulated in human dysplastic renal tissue. A-F: IHC on 1-year post-natal human renal dysplastic tissue. A and D: PAX2 marks undifferentiated mesenchyme in dysplastic human renal tissue (arrow), and is not expressed in normal renal tissue. B and E: Within dysplastic renal tissue, undifferentiated mesenchyme demonstrates increased levels of active $\beta$-catenin compared with normal renal tubules. $\mathbf{C}$ and $\mathbf{F}$ : Within dysplastic renal tissue, cells that express high levels of $\beta$-catenin also express GDNF (arrow), which is absent in normal kidney tissue. G: Histological analysis of 38-week fetal human dysplastic kidneys reveals ectopic formation of renal tissue (arrow). High-magnification images of $\mathbf{G}$ are shown in Supplemental Figure S5, E and F. H-J: IHC on 38-week human fetal dysplastic kidney tissue. Cytokeratin IHC on serially sectioned dysplastic tissue (H) reveals GDNF protein localizes around the uretericderived collecting ducts (arrows) (I). J: Ureteric-derived collecting ducts demonstrate high levels of nuclear $\beta$-catenin. Scale bars: $10 \mu \mathrm{m}(\mathbf{A}-\mathbf{F}$ and $\mathbf{H}-\mathbf{J}$ ); 100 $\mu \mathrm{m}(\mathbf{G})$. 
A

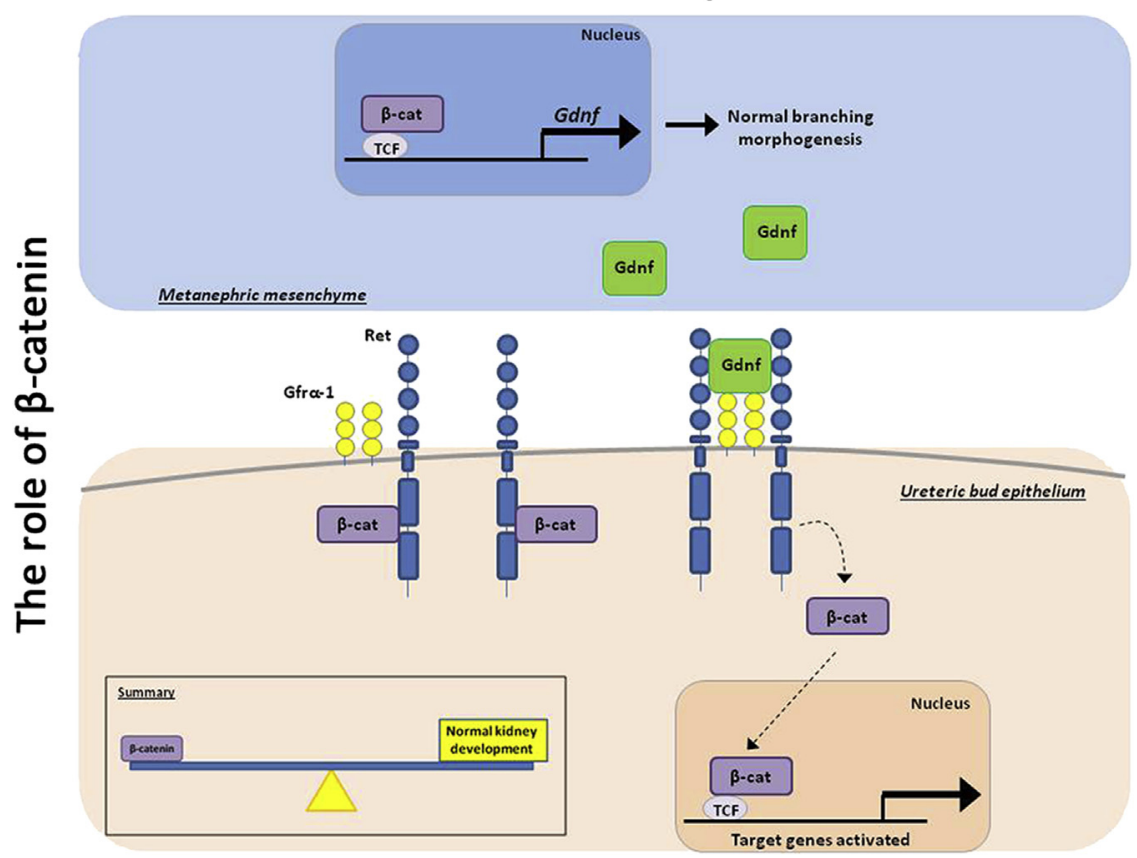

B

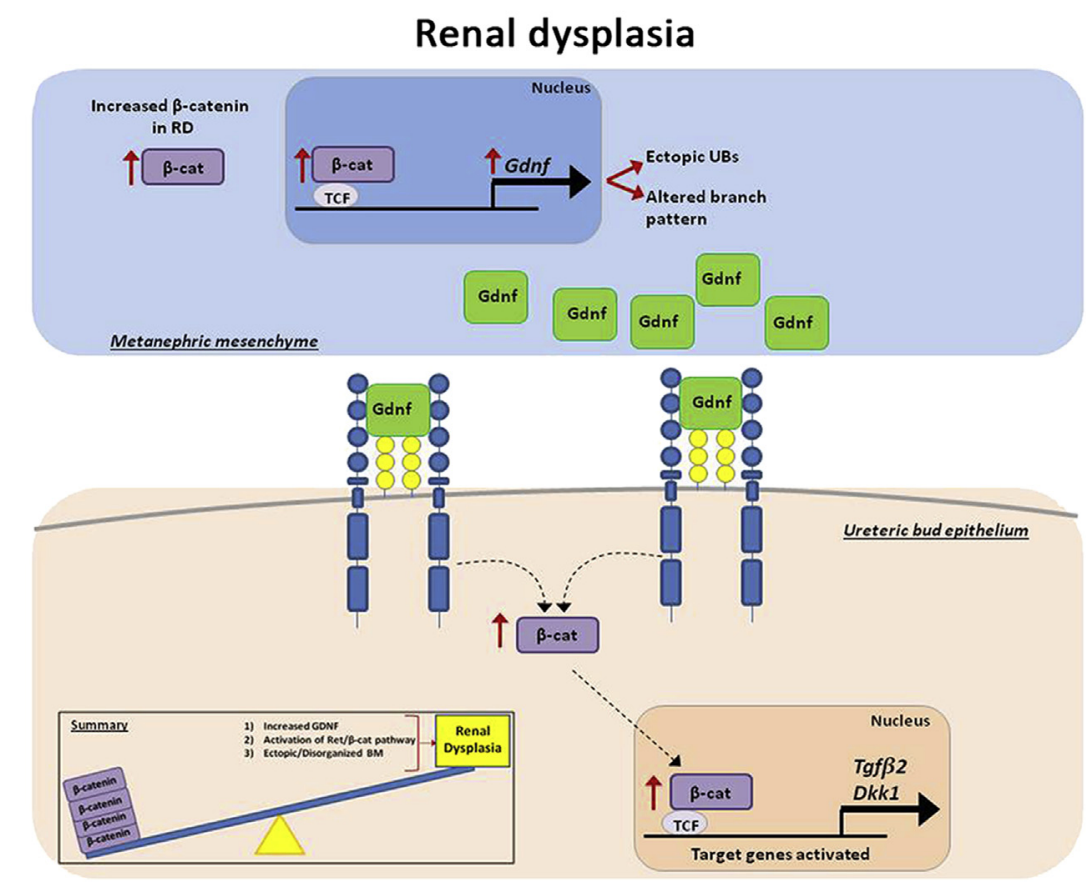

Figure 7 A paradigm demonstrating the effects of increased $\beta$-catenin in the metanephric mesenchyme. A: During normal kidney development, $\beta$-catenin directly regulates the expression of Gdnf within the metanephric mesenchyme and regulates branching morphogenesis. B: In renal dysplasia, the overexpression of $\beta$-catenin in the metanephric mesenchyme results in increased Gdnf levels, which leads to ectopic ureteric budding and disruptions in normal ureteric branch patterning. The increase in mesenchymal $\beta$-catenin results in increased Ret/ $\beta$-catenin signaling in ureteric cells, mediated by Ret activation. As another result of increased Gdnf, levels of $\beta$-catenin increase in ureteric cells mediated by Ret activation. The ectopic activation of the Ret/ $\beta$-catenin signaling pathway exacerbates the dysplastic phenotype. consensus binding site upstream of a reporter gene, we were able to demonstrate that from this Tcf/lef consensus site, $\beta$-catenin is capable of regulating $G d n f$ transcription in vitro. Previous reports have demonstrated that $\beta$-catenin acts in a molecular complex with Six 2 and binds to an enhancer region $110 \mathrm{~kb}$ upstream of the $G d n f$ transcriptional start site to regulate $G d n f$ expression. ${ }^{35}$ Our studies extend these findings by demonstrating that $\beta$-catenin is capable of binding to proximal regions (within the initial $5 \mathrm{~kb}$ ) of the $G d n f$ promoter, and from these proximal consensus sites, it regulates $G d n f$ transcription. Our studies, combined with previously published reports, highlight the complex molecular mechanisms of $\beta$-catenin-mediated Gdnf regulation, highlighting the importance of the proper spatial and temporal regulation of Gdnf expression for normal development.

Interestingly, we detected GDNF expression in kidney mesenchyme and in areas surrounding the ureteric epithelium within postnatal and fetal dysplastic human kidney 
tissue. The spatial localization of GDNF expression was in the same cells or in close proximity to cells with high levels of activated $\beta$-catenin. These findings are unusual given that, under normal circumstances, human kidney development is completed by 36 weeks' gestation, and marked by the termination of GDNF expression. Our analysis of the dysplastic human kidney tissue suggests that a similar mechanism, as seen in our mutant mouse model, is responsible for the genesis of human renal dysplasia. Together, our findings highlight a strong associative role for $\beta$-catenin in the genesis of human renal dysplasia by directly regulating the overexpression of Gdnf.

During the characterization of our mutant model, we unexpectedly observed increased $\beta$-catenin levels in the ureteric epithelium. This was surprising because previous reports demonstrated the $\operatorname{Rar} \beta 2$ promoter fragment drives Cre expression in the metanephric mesenchyme and not in the ureteric epithelium. ${ }^{32,42}$ Our investigation of Rar $\beta 2-C r e$ recombinase activity using a ROSA reporter mouse confirmed that in our Rarß2-Cre mice, recombinase was active within the mesenchyme cell population and absent from the ureteric tissue, confirming previous findings ${ }^{32,42}$ (Supplemental Figure S1). These results suggested that additional mechanisms are accounting for the increase in nuclear $\beta$-catenin within the ureteric epithelium in $\beta$-cat ${ }^{G O F-M M}$ mutants. Interestingly, studies in thyroid carcinoma cells identified a novel signaling pathway in which the Ret receptor directly interacts with and phosphorylates $\beta$-catenin at tyrosine residues. ${ }^{36}$ This results in $\beta$-catenin escaping the degradation machinery, resulting in an accumulation of $\beta$-catenin in the nucleus, where it activates specific transcriptional programs. ${ }^{36}$ We demonstrate in embryonic kidney lysates that $\beta$-catenin does directly interact with the Ret receptor, and on Ret activation by Gdnf, it is released from the receptor. Further evidence supporting the involvement of the Ret/ $\beta$-catenin signaling pathway comes from kidney explants isolated from Tcf reporter mice. These mice demonstrate increased Tcfmediated reporter activity in the ureteric epithelium on stimulation by GDNF. These studies demonstrate the presence of a previously uncharacterized Ret/ $\beta$-catenin signaling pathway during kidney development. It will be interesting to determine whether specific transcriptional programs controlling distinct biological processes necessary for ureteric branching are mediated via this novel pathway.

Because kidney development progresses in $\beta$-cat ${ }^{\text {GOF-MM }}$ mutants, we observed an unexpected reduction in the number of branch generations in vivo, because overexpression of Gdnf typically leads to increases in branching. Furthermore, kidney explants cultured from $\beta$-cat ${ }^{G O F-M M}$ mice demonstrated stalled branching morphogenesis at the initial T-shaped stage of kidney development, suggesting a mechanism that inhibits branching morphogenesis beyond E14.5. We suspected the involvement of this novel Ret/ $\beta$ catenin signaling pathway in inhibiting the branch generation in $\beta$-cat ${ }^{G O F-M M}$ because our previous work in which we overexpressed $\beta$-catenin exclusively in the ureteric epithelium caused an overexpression of $T g f b 2$ and $D k k 1$, resulting in an inhibition of branching morphogenesis. ${ }^{25}$ Interestingly, the generation of Tcf/LacZ; $\beta$-cat ${ }^{G O F-M M}$ mice demonstrated a marked increase in $\beta$-galactosidase reporter gene activation in the ureteric tissue, demonstrating the activation of a $\beta$-catenin-mediated pathway. Once activated by the Gdnf overexpression, we suspect this novel pathway regulates genes that act to inhibit ureteric branching, as shown in our earlier studies. ${ }^{25}$ In support of a role for this pathway in the genesis of renal dysplasia, we demonstrate within dysplastic human tissue that ureteric-derived tubules that were bordered by GDNF demonstrated high levels of nuclear $\beta$-catenin. Given these findings, overexpression of $\beta$-catenin in the metanephric mesenchyme also leads to elevations in $\beta$-catenin within the ureteric epithelium and demonstrates a non-cell-autonomous role for $\beta$-catenin in the genesis of renal dysplasia.

The kidney phenotype in $\beta$-cat ${ }^{G O F-M M}$ mutants differs from that observed in mice generated by Park et al. ${ }^{19}$ Their study generated mice with $\beta$-catenin stabilization exclusively in the cap mesenchyme. Mutant mice exhibited renal agenesis at birth, whereas embryonically, they were characterized by a lack of nephron formation and reduced epithelial branching. ${ }^{19}$ In contrast, $\beta$-cat ${ }^{G O F-M M}$ mutants exhibited large, misshapen, and lobular dysplastic kidneys at birth. Embryonically, $\beta$-cat ${ }^{G O F-M M}$ mutants demonstrated an intact nephrogenic program and focal zones of undifferentiated nephrogenic structures. Mosaic Rar $\beta$-Cre activity, leading to $\beta$-catenin stabilization in subsets of mesenchyme and stromal cells, may account for the vastly different renal phenotype. However, a careful analysis of Rar $\beta$-Cre activity by Kobayashi et $\mathrm{al}^{32}$ and Di Giovanni et $\mathrm{al}^{42}{ }^{42}$ using a ROSA reporter strain, demonstrated that few stromal or mesenchyme cells escaped $\mathrm{Cr}$ recombination events. Therefore, it is highly unlikely that mosaic expression was a contributing factor. Instead, the variation in the renal phenotypes likely results from the different $\mathrm{Cre}$ transgenic mice lines. Park et $\mathrm{al}^{19}$ stabilized $\beta$-catenin using a Six2-Cre mouse model that limits $\mathrm{Cre}$ activity to the cap mesenchyme. In contrast, Rar $\beta$-Cre is active in the metanephric mesenchyme and renal stroma. ${ }^{32,42}$ Studies have emphasized the importance of the renal stroma in the regulation of nephrogenesis and MET. ${ }^{43-45}$ Recently, Das et al ${ }^{46}$ identified that stromally expressed factors promote differentiation of nephron progenitors in a paracrine-dependent manner. These studies highlight that stabilization of $\beta$-catenin in the renal stroma likely has essential roles in regulating nephrogenesis in a paracrine-dependent manner. In support of this model, in vitro stabilization of $\beta$-catenin in isolated mesenchymal and stromal cells induced MET and subsequent nephron formation. ${ }^{47}$ Further studies will be required to elucidate $\beta$ catenin's role in the renal stroma and to identify the regulatory molecules that effect nephrogenesis.

Although $\beta$-catenin plays essential functions during normal renal development, its role in the genesis of renal 
dysplasia is not well described. ${ }^{19,22,23}$ Our studies support a two-hit mechanism in which overexpression of $\beta$-catenin in the metanephric mesenchyme has cell-autonomous and non-cell-autonomous effects, leading to the genesis of renal dysplasia (Figure 7). The first hit occurs upstream of the Ret receptor because the overexpression of $\beta$-catenin in the metanephric mesenchyme directly up-regulates $G d n f$ transcription, resulting in ectopic and disorganized ureteric branch patterning. The second hit occurs downstream of the Ret receptor. The overexpression of $\beta$-catenin in the metanephric mesenchyme leads to the activation of a novel Ret/ $\beta$-catenin-mediated signaling pathway via Gdnf stimulation, resulting in increased $\beta$-catenin transcriptional activity in the ureteric epithelium, which inhibits ureteric branching. Therefore, overexpression of $\beta$-catenin in the metanephric mesenchyme results in cell-autonomous and non-cellautonomous effects that lead to the genesis of renal dysplasia.

\section{Acknowledgment}

We thank Dr. Jan Janson for the human dysplastic tissue.

\section{Supplemental Data}

Supplemental material for this article can be found at http://dx.doi.org/10.1016/j.ajpath.2014.01.018.

\section{References}

1. Winyard P, Chitty LS: Dysplastic kidneys. Semin Fetal Neonatal Med 2008, 13:142-151

2. Neu AM, Ho PL, McDonald RA, Warady BA: Chronic dialysis in children and adolescents: the 2001 NAPRTCS Annual Report. Pediatr Nephrol 2002, 17:656-663

3. Hu MC, Piscione TD, Rosenblum ND: Elevated SMAD1/beta-catenin molecular complexes and renal medullary cystic dysplasia in ALK3 transgenic mice. Development 2003, 130:2753-2766

4. Woolf AS, Price KL, Scambler PJ, Winyard PJ: Evolving concepts in human renal dysplasia. J Am Soc Nephrol 2004, 15:998-1007

5. Riccabona M, Ring E: Renal Agenesis, Dysplasia, Hypoplasia and Cystic Diseases of the Kidney Pediatric Uroradiology. Edited by Fotter R. Berlin, Germany, Springer Berlin Heidelberg, 2008, pp 187-221

6. Goodyer P: Renal Dysplasia/Hypoplasia. Edited by Avner E, Harmon W, Niaudet P, Yoshikawa N. Berlin, Germany, Springer Berlin Heidelberg, 2009, pp 107-120

7. Rosenblum ND, Waters AM: Overview of congenital anomalies of kidney and urinary tract (CAKUT). TK Mattoo, LS Baskin, MS Kim (Eds). In UpToDate [Internet]. 2014. Available at: http://www.uptodate.com/ contents/overview-of-congenital-anomalies-of-the-kidney-and-urinarytract-cakut, last updated January 21, 2014

8. Saxen L, Sariola H: Early organogenesis of the kidney. Pediatr Nephrol 1987, 1:385-392

9. Costantini F, Shakya R: GDNF/Ret signaling and the development of the kidney. Bioessays 2006, 28:117-127

10. Bridgewater D, Rosenblum ND: Stimulatory and inhibitory signaling molecules that regulate renal branching morphogenesis. Pediatr Nephrol 2009, 24:1611-1619

11. Takahashi M: The GDNF/RET signaling pathway and human diseases. Cytokine Growth Factor Rev 2001, 12:361-373
12. Fisher CE, Michael L, Barnett MW, Davies JA: Erk MAP kinase regulates branching morphogenesis in the developing mouse kidney. Development 2001, 128:4329-4338

13. Tang MJ, Cai Y, Tsai SJ, Wang YK, Dressler GR: Ureteric bud outgrowth in response to RET activation is mediated by phosphatidylinositol 3-kinase. Dev Biol 2002, 243:128-136

14. Pichel JG, Shen L, Sheng HZ, Granholm AC, Drago J, Grinberg A, Lee EJ, Huang SP, Saarma M, Hoffer BJ, Sariola H, Westphal H: Defects in enteric innervation and kidney development in mice lacking GDNF. Nature 1996, 382:73-76

15. Schuchardt A, D'Agati V, Larsson-Blomberg L, Costantini F, Pachnis V: Defects in the kidney and enteric nervous system of mice lacking the tyrosine kinase receptor Ret. Nature 1994, 367: 380-383

16. Carroll TJ, Park JS, Hayashi S, Majumdar A, McMahon AP: Wnt9b plays a central role in the regulation of mesenchymal to epithelial transitions underlying organogenesis of the mammalian urogenital system. Dev Cell 2005, 9:283-292

17. Itaranta P, Lin Y, Perasaari J, Roel G, Destree O, Vainio S: Wnt-6 is expressed in the ureter bud and induces kidney tubule development in vitro. Genesis 2002, 32:259-268

18. Yu J, Carroll TJ, Rajagopal J, Kobayashi A, Ren Q, McMahon AP: A Wnt7b-dependent pathway regulates the orientation of epithelial cell division and establishes the cortico-medullary axis of the mammalian kidney. Development 2009, 136:161-171

19. Park JS, Valerius MT, McMahon AP: Wnt/beta-catenin signaling regulates nephron induction during mouse kidney development. Development 2007, 134:2533-2539

20. Gordon MD, Nusse R: Wnt signaling: multiple pathways, multiple receptors, and multiple transcription factors. J Biol Chem 2006, 281 : 22429-22433

21. MacDonald BT, Tamai K, He X: Wnt/beta-catenin signaling: components, mechanisms, and diseases. Dev Cell 2009, 17:9-26

22. Bridgewater D, Cox B, Cain J, Lau A, Athaide V, Gill PS, Kuure S, Sainio K, Rosenblum ND: Canonical WNT/beta-catenin signaling is required for ureteric branching. Dev Biol 2008, 317:83-94

23. Marose TD, Merkel CE, McMahon AP, Carroll TJ: Beta-catenin is necessary to keep cells of ureteric bud/Wolffian duct epithelium in a precursor state. Dev Biol 2008, 314:112-126

24. Grote D, Boualia SK, Souabni A, Merkel C, Chi X, Costantini F, Carroll T, Bouchard M: Gata3 acts downstream of beta-catenin signaling to prevent ectopic metanephric kidney induction. PLoS Genet 2008, 4:e1000316

25. Bridgewater D, Di Giovanni V, Cain JE, Cox B, Jakobson M, Sainio K, Rosenblum ND: beta-Catenin causes renal dysplasia via upregulation of Tgfbeta2 and Dkk1. J Am Soc Nephrol 2011, 22:718-731

26. Harada N, Miyoshi H, Murai N, Oshima H, Tamai Y, Oshima M, Taketo MM: Lack of tumorigenesis in the mouse liver after adenovirus-mediated expression of a dominant stable mutant of betacatenin. Cancer Res 2002, 62:1971-1977

27. Cheon SS, Cheah AY, Turley S, Nadesan P, Poon R, Clevers H, Alman BA: beta-Catenin stabilization dysregulates mesenchymal cell proliferation, motility, and invasiveness and causes aggressive fibromatosis and hyperplastic cutaneous wounds. Proc Natl Acad Sci U S A 2002, 99:6973-6978

28. Brault V, Moore R, Kutsch S, Ishibashi M, Rowitch DH, McMahon AP, Sommer L, Boussadia O, Kemler R: Inactivation of the beta-catenin gene by Wnt1-Cre-mediated deletion results in dramatic brain malformation and failure of craniofacial development. Development 2001, 128:1253-1264

29. Soriano P: Generalized lacZ expression with the ROSA26 Cre reporter strain. Nat Genet 1999, 21:70-71

30. Livak KJ, Schmittgen TD: Analysis of relative gene expression data using real-time quantitative PCR and the 2(-Delta Delta C(T)) Method. Methods 2001, 25:402-408

31. Huelsken J, Behrens J: The Wnt signalling pathway. J Cell Sci 2002, 115:3977-3978 
32. Kobayashi A, Kwan KM, Carroll TJ, McMahon AP, Mendelsohn CL, Behringer RR: Distinct and sequential tissue-specific activities of the LIM-class homeobox gene Lim1 for tubular morphogenesis during kidney development. Development 2005, 132:2809-2823

33. Majumdar A, Vainio S, Kispert A, McMahon J, McMahon AP: Wnt11 and Ret/Gdnf pathways cooperate in regulating ureteric branching during metanephric kidney development. Development 2003, 130: 3175-3185

34. Tanwar PS, Kaneko-Tarui T, Zhang L, Rani P, Taketo MM, Teixeira J: Constitutive WNT/beta-catenin signaling in murine Sertoli cells disrupts their differentiation and ability to support spermatogenesis. Biol Reprod 2010, 82:422-432

35. Park JS, Ma W, O’Brien LL, Chung E, Guo JJ, Cheng JG, Valerius MT, McMahon JA, Wong WH, McMahon AP: Six2 and Wnt regulate self-renewal and commitment of nephron progenitors through shared gene regulatory networks. Dev Cell 2012, 23:637-651

36. Gujral TS, van Veelen W, Richardson DS, Myers SM, Meens JA, Acton DS, Dunach M, Elliott BE, Hoppener JW, Mulligan LM: A novel RET kinase-beta-catenin signaling pathway contributes to tumorigenesis in thyroid carcinoma. Cancer Res 2008, 68:1338-1346

37. Thomas R, Sanna-Cherchi S, Warady BA, Furth SL, Kaskel FJ, Gharavi AG: HNF1B and PAX2 mutations are a common cause of renal hypodysplasia in the CKiD cohort. Pediatr Nephrol 2011, 26:897-903

38. Jain S, Suarez AA, McGuire J, Liapis H: Expression profiles of congenital renal dysplasia reveal new insights into renal development and disease. Pediatr Nephrol 2007, 22:962-974

39. Brophy PD, Ostrom L, Lang KM, Dressler GR: Regulation of ureteric bud outgrowth by Pax2-dependent activation of the glial derived neurotrophic factor gene. Development 2001, 128:4747-4756
40. Kume T, Deng K, Hogan BL: Murine forkhead/winged helix genes Foxc1 (Mf1) and Foxc2 (Mfh1) are required for the early organogenesis of the kidney and urinary tract. Development 2000, 127: $1387-1395$

41. Grieshammer U, Le M, Plump AS, Wang F, Tessier-Lavigne M, Martin GR: SLIT2-mediated ROBO2 signaling restricts kidney induction to a single site. Dev Cell 2004, 6:709-717

42. Di Giovanni V, Alday A, Chi L, Mishina Y, Rosenblum ND: Alk3 controls nephron number and androgen production via lineagespecific effects in intermediate mesoderm. Development 2011, 138: $2717-2727$

43. Hatini V, Huh SO, Herzlinger D, Soares VC, Lai E: Essential role of stromal mesenchyme in kidney morphogenesis revealed by targeted disruption of Winged Helix transcription factor BF-2. Genes Dev 1996, 10:1467-1478

44. Levinson RS, Batourina E, Choi C, Vorontchikhina M, Kitajewski J, Mendelsohn CL: Foxd1-dependent signals control cellularity in the renal capsule, a structure required for normal renal development. Development 2005, 132:529-539

45. Cullen-McEwen LA, Caruana G, Bertram JF: The where, what and why of the developing renal stroma. Nephron Exp Nephrol 2005, 99: $\mathrm{e} 1-\mathrm{e} 8$

46. Das A, Tanigawa S, Karner CM, Xin M, Lum L, Chen C, Olson EN, Perantoni AO, Carroll TJ: Stromal-epithelial crosstalk regulates kidney progenitor cell differentiation. Nat Cell Biol 2013, 15:1260

47. Kuure S, Popsueva A, Jakobson M, Sainio K, Sariola H: Glycogen synthase kinase- 3 inactivation and stabilization of beta-catenin induce nephron differentiation in isolated mouse and rat kidney mesenchymes. J Am Soc Nephrol 2007, 18:1130-1139 